Review

\title{
The Potential of Nrf2 Activation as a Therapeutic Target in Systemic Lupus Erythematosus
}

\author{
Michelle T. Barati and Dawn J. Caster* \\ Division of Nephrology and Hypertension, Department of Medicine, Health Sciences Campus, \\ University of Louisville, Louisville, KY 40202, USA; michelle.barati@louisville.edu \\ * Correspondence: dawn.caster@louisville.edu
}

check for updates

Citation: Barati, M.T.; Caster, D.J. The Potential of Nrf2 Activation as a

Therapeutic Target in Systemic Lupus Erythematosus. Metabolites 2022, 12, 151. https://doi.org/10.3390/ metabo12020151

Academic Editor: Tamara

K. Nowling

Received: 26 November 2021

Accepted: 3 February 2022

Published: 6 February 2022

Publisher's Note: MDPI stays neutral with regard to jurisdictional claims in published maps and institutional affiliations.

Copyright: () 2022 by the authors Licensee MDPI, Basel, Switzerland. This article is an open access article distributed under the terms and conditions of the Creative Commons Attribution (CC BY) license (https:// creativecommons.org/licenses/by/ $4.0 /)$.

\begin{abstract}
Inflammation and oxidative stress are well established in systemic lupus erythematosus (SLE) and are critical to the pathogenesis of autoimmune diseases. The transcription factor NF-E2 related factor 2 (Nrf2) is a central regulator of cellular anti-oxidative responses, inflammation, and restoration of redox balance. Accumulating reports support an emerging role for the regulation of Nrf2 in SLE. These include findings on the development of lupus-like autoimmune nephritis and altered immune cell populations in mice lacking Nrf2, as well as decreased Nrf2 abundance in the dendritic cells of patients with SLE. Nrf2-inducing agents have been shown to alleviate oxidative and inflammatory stress and reduce tissue injury in SLE mouse models. Since Nrf2 expression can be increased in activated $\mathrm{T}$ cells, the precise role of Nrf2 activation in different immune cell types and their function remains to be defined. However, targeting Nrf2 for the treatment of diseases associated with oxidative stress and inflammation, such as SLE, is promising. As investigation of Nrf2-inducing agents in clinical trials grows, defining the signaling and molecular mechanisms of action and downstream effects in response to different Nrf2-inducing agents in specific cells, tissues, and diseases, will be critical for effective clinical use.
\end{abstract}

Keywords: systemic lupus erythematosus (SLE); lupus nephritis (LN); oxidative stress; Nrf2

\section{Introduction}

Systemic lupus erythematosus (SLE) is a complex autoimmune disease with genetic, epigenetic, environmental, hormonal, and immune regulatory factors [1]. Abnormal clearance of apoptotic bodies followed by autoantibody production to nuclear antigens and loss of self-tolerance are key to SLE development. These autoantibody/antigen complexes (immune complexes) are deposited in organs and tissues causing inflammation and, ultimately, tissue damage. Both innate and adaptive immune responses contribute to the development of SLE. Neutrophils contribute through the release of neutrophil extracellular traps (NETs), which contain chromatin fibrils and histones that add to the nuclear antigen burden in patients with SLE [2]. Macrophages contribute through the decreased clearance of apoptotic bodies [3] and a shift in macrophage profiles to the more classic/M1 (pro-inflammatory) phenotype, compared to the non-classic/M2 (pro-resolving/repair) phenotype [4]. Antigenpresenting cells, especially dendritic cells, present nuclear autoantigens to T cells, leading to activation and differentiation. Nuclear antigens from apoptotic bodies and NETs also induce interferon $\alpha$ production by plasmacytoid dendritic cells, which amplifies immune responses. All of these cells release cytokines to continually promote inflammation, dendritic cell maturation and T cell activation [5]. Activated T cells help to induce autoreactive $B$ cells and antibody-producing B cells. Immune complex formation further amplifies and perpetuates the immune response and inflammation. SLE T cells are further characterized by reduced interleukin 2 and increased interleukin 17 and the generation of pathogenic Th17 cells [1,6]. Kidney involvement, characterized by immune complex deposition in the kidneys, termed lupus nephritis (LN), occurs in $50-60 \%$ of patients with SLE [7]. This leads 
to increased morbidity and mortality in patients with SLE. Immunosuppressive regimens remain the cornerstone of LN treatments. The rate of complete response with standard of care therapies remains under $50 \%$ at 12 months [2,8]. Novel therapies having improved efficacy and reduced toxicity are needed.

An imbalance between the cellular generation of reactive oxygen species (ROS) and anti-oxidative capacity results in oxidative stress, which is exacerbated by inflammation, another key player in aging and the progression of chronic diseases such as SLE [9-11]. Similarly, oxidative stress can lead to, or augment, inflammation [12] and may be a key immune regulatory factor contributing to the initial aberrant SLE immune response [10]. ROS contribute to abnormal cell death signals, enhanced apoptosis, and delayed clearance of apoptotic cells [6], and oxidative modification of self-antigens can trigger autoantibody production, which can lead to organ damage in SLE. While the presence of oxidative stress in different cell and tissue types is clearly evident in SLE and exposure to increased ROS alters activation of cells (e.g., neutrophils, T cells, and peripheral blood mononuclear cells), the overall role of oxidative stress in SLE remains unclear $[6,13]$. For example, the failure to generate sufficient ROS for an oxidative burst in mice with a mutated neutrophil cytosolic factor 1, a subunit of NADPH oxidase, leads to development of autoimmune disease [14]. The transcription factor Nrf2 (NF-E2 related factor 2), is a central regulator of cellular anti-oxidative and anti-inflammatory responses. A growing number of reports on the regulation of oxidative and inflammatory stress support a potentially significant role for Nrf2 in SLE [6]. Nrf2 deficiency leads to lupus-like autoimmune syndrome and nephritis in aged female mice, suggesting a direct role for Nrf2 deficiency in the pathogenesis of autoimmune disease [15]. In addition, increased oxidative DNA damage, Nrf2, and an Nrf2 transcriptional target in the glomeruli of SLE patients potentially demonstrated a tissue response to oxidative stress associated with SLE [16]. Current medications used to treat LN have varying effects on Nrf2 signaling. Corticosteroids, which are widely used in SLE and LN, indirectly downregulate Nrf2 [6]. However, Nrf2 activity appears to be preserved by hydroxychloroquine and mycophenolate mofetil. Cyclophosphamide, an alkylating agent used in the treatment of LN, is associated with high oxidative stress, which can lead to hepatotoxicity and myelotoxicity, and Nrf2 activation may ameliorate these effects [6,10]. Thus, Nrf2 regulation in SLE may be critical for maintaining redox homeostasis, normal immune responses, and decreasing tissue injury.

\section{Nrf2}

Nrf2 is a central regulator of cytoprotection and redox homeostasis in cells. This is accomplished through induction of Nrf2 target genes, which include enzymes involved in antioxidative responses and phase II detoxification processes. As shown in Figure 1, Nrf2 also plays a role in inflammation, cell proteostasis through transcriptional regulation of proteasomal subunit proteins and autophagy, as well as in intermediary metabolism by regulating enzymes of the pentose phosphate pathway, purine metabolism, and lipogenesis [17-21].

Nrf2 is a "cap ' $n$ ' collar"-basic region leucine zipper transcription factor and its abundance is regulated through binding to Keap1 (Kelch ECH-associating protein 1) in the cytosol [22]. Binding to Keap1 is done through ETGE and DLG binding motifs on Nrf2. Keap1 is an adaptor protein for cullin-3 E3 ubiquitin ligase and this association leads to ubiquitination of Nrf2 and proteasomal degradation in unstressed cells (Figure 2A). During cell stress conditions, such as oxidative stress, Keap1 is the main sensor of stress through modification of specific cysteine residues on Keap1 by oxidants and electrophiles (Figure 2B). These modifications alter its association with Nrf2, allowing it to escape ubiquitination and proteasomal degradation and translocate to the nucleus. Stress simultaneously activates cell-signaling pathways and kinases capable of directly phosphorylating Nrf2 and modulating its localization and/or transcriptional activity. Examples of kinases known to phosphorylate Nrf2 include protein kinase C (PKC) [23], casein kinase 2 [24], mitogen activated protein kinases (MAPKs) [25], and PERK (Protein kinase RNA-like endoplasmic reticulum kinase) [26]. Direct phosphorylation of Nrf2 by PERK links it to cytoprotective 
signaling associated with an unfolded protein response due to endoplasmic reticulum stress. The functional consequences of Nrf2 phosphorylation at specific residues are dependent on the type of cell, stress, or stimulus. For example, phosphorylation of Nrf2 serine-40 by PKC has been shown to both increase [23] and not alter [27] Nrf2 nuclear accumulation. Similarly, regulation of MAPK signaling by pharmacologic and genetic approaches alters Nrf2 transcriptional activation [28], but substitution of specific Nrf2 residues phosphorylated by MAPKs with alanine, resulted in limited effects on Nrf2 transcriptional activation [25]. These findings suggest that phosphorylation at specific residues may not play solitary roles in Nrf2 function but rather play a part in a complex interplay of multiple signaling events and Nrf2 modifications involved in its activation. In the nucleus, Nrf2 forms heterodimers with small Maf proteins and binds to antioxidant-response element (ARE) sites in the promoter regions of its target genes to initiate transcription.

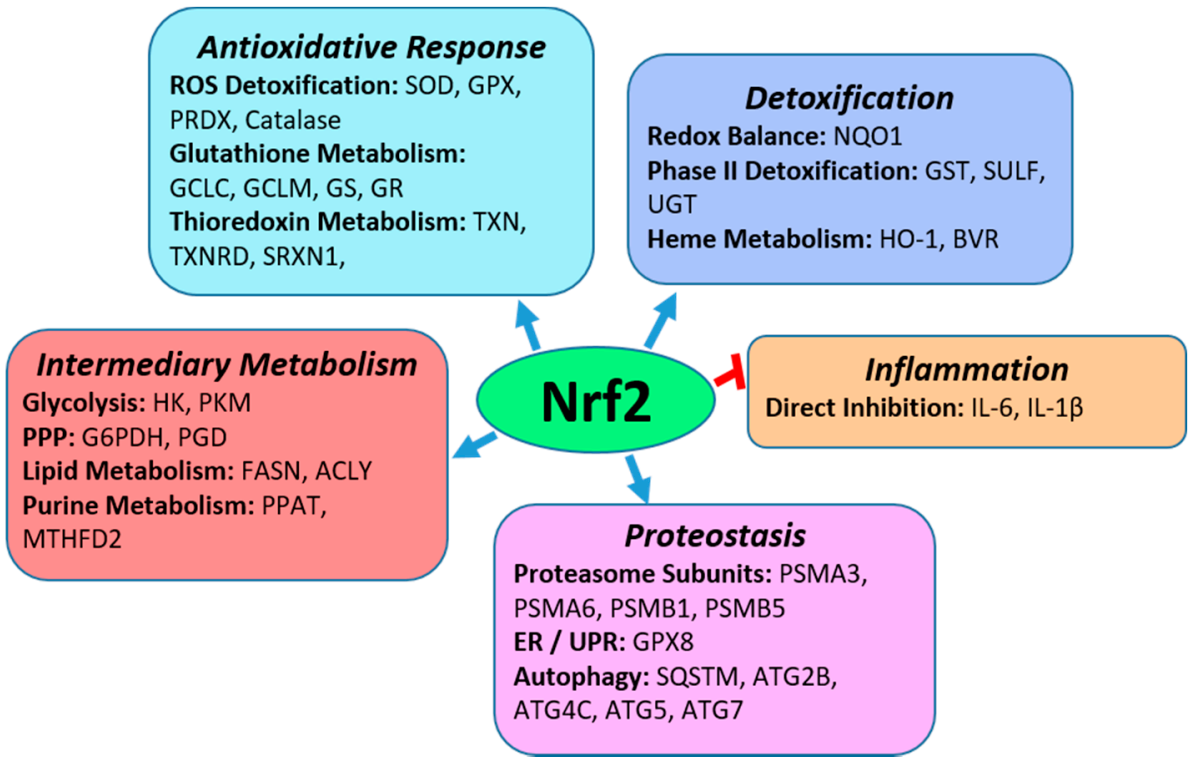

Figure 1. Biological Functions of Nrf2. As a transcription factor, Nrf2 is a central regulator of anti-oxidative responses and detoxification mechanisms. It also induces the expression of genes in intermediary metabolism and multiple pathways in proteostasis such as the proteasomal degradation of proteins and degradation of protein aggregates through autophagy. In addition, Nrf2 directly inhibits inflammation by inhibiting expression of IL- 6 and IL-1 $\beta$. Specific pathways that Nrf2 regulates in each biological functional group are in bold with examples of specific Nrf2 transcriptional gene targets in each pathway. Abbreviations of Nrf2 target genes in the pathways: SOD-superoxide dismutase; GPX, glutathione peroxidase; PRDX-peroxiredoxin; GCLC-glutamyl-cysteine ligase, catalytic; GCLMglutamyl-cysteine ligase, modifier; GS-glutathione synthetase; GR-glutathione reductase; TXNthioredoxin; TXNRD-thioredoxin reductase; SRXN-sulfiredoxin; NQO1-NAD(P)H dehydrogenase quinone-1; GST-glutathione-S-transferase; SULT-sulfotransferase; UGT-UDP-glucuronosyltransferase; HO-1-heme oxygenase 1; BVR-biliverdin reductase; IL-6-interleukin 6; IL-1 $\beta$-interleukin 1 $\beta$; PSMAproteasome 20S subunit alpha; PSMB-proteasome 20S subunit beta; SQSTM-Sequestosome; ATG2Bautophagy related 2B; ATG4C-autophagy related 4C cysteine peptidase; ATG5 or 7-autophagy related 5 or 7; HK-hexokinase; PKM-pyruvate kinase muscular; G6PDH-glucose 6 phosphate dehydrogenase; PGD- 6-phosphogluconate dehydrogenase; FASN-fatty acid synthase; ACLY-ATP-citrate lyase; PPAT-Phosphoribosyl Pyrophosphate Amidotransferase; MTHFD2-Methylenetetrahydrofolate Dehydrogenase/Cyclohydrolase. Abbreviations in pathways (bold font): ROS-reactive oxygen species; ER-endoplasmic reticulum; UPR-unfolded protein response; PPP-pentose phosphate pathway. 
A

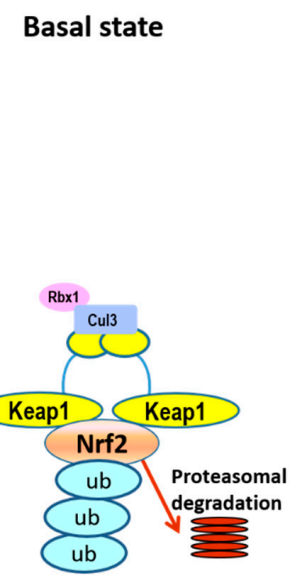

B

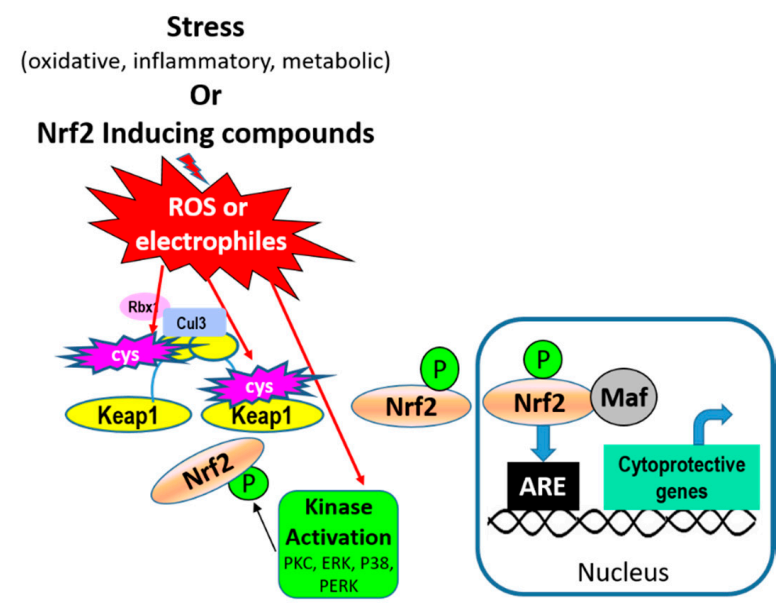

Figure 2. Pathways of Nrf2 activation. (A) In basal conditions Keap1 (Kelch ECH-associating protein 1) dimers associate with Nrf2 in the cytosol by binding to two different motifs on Nrf2. Keap1 is an adaptor protein for cullin-3 (Cul3) E3 ubiquitin ligase and its associating protein Rbx1, and this leads to ubiquitination of Nrf2 and proteasomal degradation. (B) In cell-stress conditions, specific cysteine residues on Keap1 are modified (marked in pink blasts), altering its association with Nrf2 and allowing Nrf2 to escape ubiquitination and proteasomal degradation. Simultaneously, stress conditions activate cell signaling pathways, kinase activation, and Nrf2 phosphorylation. Examples of kinases known to phosphorylate Nrf2 include PKC (protein kinase C), PERK (Protein kinase RNA-like endoplasmic reticulum kinase), and p38 MAPK (mitogen activated protein kinase). Together, these signals allow Nrf2 to escape proteasomal degradation and translocate to the nucleus. In the nucleus, Nrf2 forms heterodimers with small Maf proteins and binds to antioxidant-response element (ARE) sites in the promoter regions of its gene targets (examples listed in Figure 1).

\subsection{Nrf2 Regulation of Anti-Oxidative Responses and Cytoprotection}

Nrf2 regulates redox homeostasis and combats oxidative stress through multiple mechanisms. It induces expression of enzymes directly involved in detoxifying ROS, such as superoxide dismutase (SOD), to break down superoxide, as well as glutathione peroxidases (GPXs), peroxiredoxins (PRDXs), and catalase, to metabolize hydrogen peroxide [29-31]. Glutathione is critical for redox homeostasis, the response to oxidative stress, and functioning of glutathione peroxidases, and its synthesis and metabolism is regulated by Nrf2. The first rate-limiting step in glutathione synthesis is the reaction of glutamate with cysteine to form $\gamma$-glutamylcysteine, which is catalyzed by glutamate cysteine ligase (GCL). GCL is composed of catalytic (GCLC) and modifier (GCLM) subunits, both of which are Nrf2 transcriptional targets [30]. Glutathione synthetase, also a target of Nrf2 [32], catalyzes the second reaction in glutathione synthesis between $\gamma$-glutamylcysteine and glycine. Nrf2 also regulates the Slc7A11 gene, which encodes the $\mathrm{xCT}$ subunit of the cystine/glutamate transporter. Cystine is reduced to cysteine, which shows that Nrf2 plays a role in maintaining the necessary supply of a glutathione precursor. Nrf2 also plays a crucial role in phase II detoxification processes, of which glutathione plays an important role. The breakdown/inactivation of peroxides by GPXs requires reduced glutathione, and this reaction results in the oxidation of glutathione. Oxidized glutathione is reduced by glutathione reductase (GR), another Nrf2 transcriptional target [30]. Thus, Nrf2 regulation of the glutathione precursor supply, synthesis, metabolism, and recycling, contributes to ROS detoxification. The thioredoxin (TXN) antioxidant system also contributes to the redox balance by maintaining a reducing environment. It accomplishes this by reducing disulfide bridges, and interacting with reductive enzymes like PRDXs which catalyze the reduction of hydroperoxides, hydrogen peroxide, and peroxynitrite. PRDXs are oxidized during the catalysis of these molecules, and TXN in turn catalyzes the reduction of PRXDs. 
Nrf2 induces expression of multiple proteins/enzymes in the TXN system, including TXN, thioredoxin reductase and sulfiredoxin [31].

Electrophilic quinones can have oxidative effects and the Nrf2 target NQO1 $(\mathrm{NAD}(\mathrm{P}) \mathrm{H}$ dehydrogenase quinone-1) is a cytoplasmic two-electron reductase $[30,33]$ that can detoxify these species. Like quinones, heme can be a source of reactive species and heme oxygenase 1 (HO-1) is an important Nrf2-regulated cytoprotective enzyme [34] involved in oxidative heme cleavage. The reaction results in the generation of biliverdin, $\mathrm{Fe}^{2+}$, and carbon monoxide (CO). Biliverdin reductase, another Nrf2 target [35], reduces biliverdin to bilirubin. Bilirubin, $\mathrm{CO}$, and ferritin, have antioxidant and anti-inflammatory properties [36]. Another way that Nrf2 maintains redox homeostasis is by producing NADPH, a co-factor for NQO1 and antioxidative enzymes. This is accomplished by Nrf2 induction of intermediary metabolism enzymes that generate NADPH, including glucose-6-phosphate dehydrogenase (G6PD), 6-phosphogluconate dehydrogenase (PGD), isocitrate dehydrogenase 1 (IDH1), and malic enzyme (ME) [37]. Other Nrf2-induced cytoprotective mechanisms include glutathione conjugation to endogenous reactive and xenobiotic molecules by glutathione-S-transferases for detoxification [38].

\subsection{Nrf2 Regulation of Inflammation}

Activation of Nrf2 in multiple models of a disease associated with oxidative stress and inflammation alleviates markers of injury and prevents disease progression. The majority of these effects are believed to be due to the upregulation of anti-oxidative and phase II detoxifying enzymes by Nrf2. However, it can also have a more direct role in regulation of inflammation. At the molecular level, Nrf2 inhibits transcription of proinflammatory IL- 6 and IL-1 $\beta$ cytokines by binding to promoter proximal regions of these genes in macrophages and inhibiting RNA Pol II recruitment [20]. In addition, Nrf2 inhibits the chemokines MIP2 (CXCL2) and MCP-1 (CCL2), because the peritoneal neutrophils in Nrf2-deficient mice showed an increased abundance of these factors in response to LPS [39]. Nrf2 also inhibits promoter activity of the adhesion molecule, VCAM1 [40], suggesting roles for Nrf2 in inhibiting adhesion and migration. There is substantial crosstalk between Nrf2 and the NFKB pro-inflammatory pathway that can play a role in regulating inflammation. Interaction of IкB kinase with Keap1 results in stabilization of the NFKB inhibitor, IKB, and thus negative regulation of NFKB [41]. In addition, MafK is a small Maf protein with which Nrf2 heterodimerizes in the nucleus. MafK promotes acetylation and the DNA-binding activity of p65 NFKB by increasing the interaction of p65 and CBP, which can be inhibited by Nrf2/MafK association [42]. Alternatively, p65 regulation of MafK/histone deacetylase 3 (HDAC3) interaction can recruit HDAC3 to Nrf2 ARE regions and suppress Nrf2 transcriptional activation [43]. Nrf2 contributes to inflammation resolution by increasing macrophage prostaglandin $\mathrm{D}$ synthase expression. This leads to increased producing 15d-PGJ2, 15-deoxy-12,14-prostaglandin J2, an Nrf2 inducer. Nrf2 in turn upregulates CD36 and HO-1 in macrophages to promote efferocytosis [44].

The regulation of Nrf2 can modulate immune cell responses by preventing oxidative tissue injury, apoptosis, and secondary necrosis, and thus to autoantigen production, $\mathrm{T}$ cell activation, and autoantibody production. The loss of Nrf2 function and detoxifying target gene induction could lead to the accumulation of reactive intermediates in tissues and the promotion of autoimmune disorders. Nrf2 may regulate $\mathrm{T}$ cell function by inhibiting pro-inflammatory Th1 cytokines, interferon- $\gamma$ and TNF $\alpha$, to promote T cell differentiation to anti-inflammatory Th2 cells [45]. Pharmacologic induction and deficiency of Nrf2 in mice is associated with altered $\mathrm{T}$ cell populations and macrophage polarization [46-48], and Nrf2 expression is increased in activated T cells [49-51] and non-classic/anti-inflammatory macrophages [48]. One study found that T-cell-specific Nrf2 activation increased the frequency of regulatory $\mathrm{T}$ cells (Tregs) and protected kidneys in a mouse model of ischemiareperfusion injury [52]. Another report shows that systemic activation of Nrf2 in mice by Keap1 knockdown prevented inflammation and lethality in the scurfy mouse model of autoimmune disease with Treg functional deficiency [53], and this was associated with 
decreased activation of T cells and cytokine production. However, cell lineage-specific Nrf2 activation through targeted Keap1 disruption in T cells, myeloid cells, and dendritic cells, either had no effect or only partially alleviated inflammation in these mice. These results suggest that Nrf2 activation in multiple immune cell types is required to combat inflammation. In lipopolysaccharide (LPS)-induced sepsis, constitutive Nrf2 activation showed protection by the expansion, and metabolic re-programming, of myeloid-derived suppressor cells (MDSC) [54], thus highlighting the role of Nrf2 in immune response regulating cells. Together, these studies demonstrated a potentially significant role for Nrf2 activation in the modulation of immune cell responses and alleviation of inflammation. Whether the beneficial effects of Nrf2 induction are indirectly related to the alleviation of stress or by direct transcriptional regulation in immune cells, remains to be defined. Furthermore, the beneficial and anti-inflammatory effects of Nrf2 activation may depend on cell/tissue and disease type.

\section{Nrf2 in SLE and LN}

\subsection{Nrf2 in Animal Models of SLE and LN}

\subsubsection{Nrf2 Deficient Mice Develop Lupus-like Autoimmune Disease}

One the most significant findings directly linking Nrf2 to SLE came from initial observations in Nrf2-deficient mice. Yoh et al. [15] first observed that $\mathrm{Nrf2} 2^{-/-}$female mice over 15 months of age had shortened lifespans and were dead within 100 weeks. Female $\mathrm{Nrf2}{ }^{-1-}$ mice developed severe glomerular lesions, and histologic examination demonstrated lupus-like nephritis by lobular formation, moderate to severe cellular proliferation, segmental sclerosis, presence of crescents, and sub-epithelial electron-dense deposits. In addition to mesangial deposits, capillary deposition of IgG, IgM, and C3 were also present. Lymphocytes and macrophages made up the majority of cells in interstitial inflammation when detected. Creatinine clearance was lower in aged female $\mathrm{Nrf2} 2^{-/}$mice, indicating renal function impairment. Serum IgG and anti-dsDNA, and markers for oxidative stress in subcutaneous fat tissue, were increased.

Later studies by Li et al. [55] reported similar findings in the renal pathology of 12-month-old female mice as well as increased IgG deposition in the liver, heart, and brain. Increased renal lipid peroxidation was seen in aged mice, whereas oxidative DNA damage was observed in the kidneys of $\mathrm{Nrf2}^{-/}$female mice as young as 5 months. In addition, the kidneys, spleen, and liver of $N r f 2^{-1-}$ mice had higher numbers of apoptotic cells and splenocytes and exhibited higher apoptotic rates. Gene-expression changes in the liver and spleen of young mice showed downregulation of detoxification genes in male and female Nrf2-deficient mice, such as glutathione S-transferases and aldehyde dehydrogenases. Furthermore, genes involved in antigen presentation, anti-DNA autoantibody generation, development of hyperplasia in the spleen, and neutrophil and monocyte chemotaxis were increased in Nrf2-deficient female mice. These gene expression changes likely contributed to altered immune responses and disease development.

Continued investigations by Ma et al. [46] determined that $\mathrm{Nrf}^{-/-}$mice had varying degrees of other inflammatory lesions such as lymphocytic sialitis, dermatitis, hyperkeratosis, myocarditis, vasculitis, pancreatitis, pleuritis, myocarditis with fibrosis, pericarditis, and conjunctivitis. Glomerulonephritis was the leading cause of death, and affected mice had higher blood urea nitrogen (BUN) and reduced hematocrit. Neoplasia was a cause of death in about $20 \%$ of the mice. Lymph node and spleen isolated T cells in the Nrf2-/mice had increased proliferation when stimulated with anti-CD3, while spleen B cell proliferation in response to LPS and anti-IgM was unchanged. Furthermore, the fraction of CD4+ lymphocytes increased while CD8+ lymphocytes decreased, suggesting dysregulated immune responses with Nrf2 loss. Lastly, this study determined that constitutive and 3-t-butyl-4-hydroxy anisol (antioxidant) inducible expression of some genes for phase II detoxification enzymes and antioxidative response were reduced in the $\mathrm{Nrf2} 2^{-/-}$mice, confirming the requirement of Nrf2 for transcription of some ARE-regulated genes critical to redox homeostasis. 
Table 1 compares the effects of Nrf2 deficiency in mice at various ages from studies by Yoh et al., Li et al., and Ma et al. $[15,46,55]$, all three of which clearly showed development of an SLE-like disease. However, differences in age of disease onset or markers of tissue injury may be related to the background strain of the $\mathrm{Nrf2} 2^{-/-}$mice. For example, there was a difference in male and female $N r f 2^{-/-}$mice survival between the studies by Yoh et al. [15] and Ma et al. [46]. In addition, kidney and liver lipid peroxidation in 24-weekold Nrf2 $2^{-/}$mice increased in the Ma et al. [46] study, but showed no difference in the study by Li et al. [55]. These differences may need to be considered in future study designs and data interpretation for comparative analyses. Together, these studies clearly defined a critical role for Nrf2 in preventing the development of SLE and potentially other autoimmune diseases and by highlighting its biologic effects. Furthermore, these studies support previous reports of the role of oxidative stress in dysregulated immune responses, such as lymphocyte activation from exposure to ROS [56], and the association of anti-oxidative and drug-metabolizing gene polymorphisms with SLE [57].

Table 1. Biological effects in Nrf2 $2^{-/-}$mice.

\begin{tabular}{|c|c|c|c|c|}
\hline$N r f 2^{-I-}$ & & & & \\
\hline Strain & Age (Weeks) & Sex & Effects in $N r f 2^{-l-}$ Mice & Refs. \\
\hline \multirow[t]{12}{*}{ ICR } & 25 & $\mathrm{M}$ and $\mathrm{F}$ & $\leftrightarrow$ kidney glomerular lesions & Yoh et al. [15] \\
\hline & 25 & $\mathrm{M}$ and $\mathrm{F}$ & $\leftrightarrow$ serum IgG, anti dsDNA & \\
\hline & 25 & $\mathrm{M}$ and $\mathrm{F}$ & $\leftrightarrow$ creatinine clearance & \\
\hline & 50 & $\mathrm{~F}$ & $\begin{array}{l}\uparrow \text { spleen/body weight ratio; } \\
\text { germinal center hyperplasia }\end{array}$ & \\
\hline & 60 & $\mathrm{~F}$ & $\uparrow$ serum IgG, anti dsDNA & \\
\hline & 60 & $\mathrm{~F}$ & $\uparrow$ kidney glomerular lesions & \\
\hline & 60 & $\mathrm{~F}$ & $\downarrow$ creatinine clearance & \\
\hline & 60 & $\mathrm{~F}$ & $\uparrow$ lipid peroxidation in subcutaneous fat & \\
\hline & 60 & $\mathrm{~F}$ & $\downarrow$ CD19-CD3+ and CD4+CD8- lymphocytes & \\
\hline & 100 & $\mathrm{~F}$ & none survived & \\
\hline & $15 ; 25 ; 50 ; 70 ; 100$ & $\mathrm{~F}$ & survival rate (\%): $100 ; 100 ; 75-80 ; 60 ; 0$ & \\
\hline & $15 ; 25 ; 50 ; 70 ; 100$ & $\mathrm{M}$ & survival rate $(\%): 100 ; 80 ; 65 ; 60 ; 20-25$ & \\
\hline \multirow[t]{5}{*}{ C57B6/129SVJ } & 20 & $\mathrm{~F}$ & $\begin{array}{c}\text { some kidney glomerular IgG, IgM, C3 } \\
\text { deposition }\end{array}$ & Li et al. [55] \\
\hline & 20 & $\mathrm{~F}$ & $\uparrow$ liver and kidney oxidative DNA damage & \\
\hline & 20 & $\mathrm{M}$ and $\mathrm{F}$ & $\begin{array}{c}\downarrow \text { expression of detoxification genes in } \\
\text { liver and spleen }\end{array}$ & \\
\hline & 24 & $\mathrm{M}$ and $\mathrm{F}$ & $\leftrightarrow$ kidney and liver lipid peroxidation & \\
\hline & 24 & $\mathrm{M}$ and $\mathrm{F}$ & $\leftrightarrow$ anti ds-DNA & \\
\hline \multirow[t]{9}{*}{ C57B6/129SVJ } & 48 & $\mathrm{~F}$ & $\uparrow a n t i$ ds-DNA & Li et al. [55] \\
\hline & 48 & $\mathrm{~F}$ & $\begin{array}{c}\text { substantial renal glomerular IgG, IgM, C3 } \\
\text { deposition }\end{array}$ & \\
\hline & 48 & $\mathrm{~F}$ & liver $\operatorname{IgG}, \mathrm{IgM}$ deposition & \\
\hline & 48 & $\mathrm{~F}$ & heart, brain IgG, IgM, C3 deposition & \\
\hline & 48 & $\mathrm{~F}$ & $\uparrow$ kidney lipid peroxidation & \\
\hline & 48 & $M$ and $F$ & $\uparrow$ liver lipid peroxidation & \\
\hline & 48 & $\mathrm{~F}$ & $\uparrow$ liver and kidney oxidative DNA damage & \\
\hline & 48 & $\mathrm{~F}$ & $\uparrow$ kidney, liver, and spleen cell apoptosis & \\
\hline & $36-48$ & $\mathrm{~F}$ & $\begin{array}{c}\uparrow \text { spontaneous apoptotic rate in } \\
\text { splenocytes }\end{array}$ & \\
\hline \multirow{5}{*}{ 129SVJ } & 24 & $\mathrm{~F}$ & $\uparrow$ kidney and liver lipid peroxidation & Ma et al. [46] \\
\hline & 36 & $\begin{array}{c}\text { not } \\
\text { specified }\end{array}$ & $\begin{array}{l}\text { average age for development of } \\
\text { glomerular lesions }\end{array}$ & \\
\hline & 48 & $\mathrm{~F}$ & $\uparrow$ kidney and liver lipid peroxidation & \\
\hline & $15 ; 25 ; 50 ; 70$ & $\mathrm{~F}$ & survival rate $(\%): 71 ; 50 ; 40-45 ; 20-25$ & \\
\hline & $15 ; 25 ; 50 ; 70$ & M & survival rate $(\%): 95 ; 85 ; 70 ; 55$ & \\
\hline
\end{tabular}

Abbreviations: M, male; F, female. $\downarrow$, decreased; $\uparrow$, increased; $\leftrightarrow$, not changed or, not different. 


\subsubsection{Effects of Nrf2 Deficiency in Mouse Models of Spontaneous SLE-like Disease}

The effects of Nrf2 deficiency were examined in MRL/lpr mice, which are defective in Fas-mediated apoptosis and spontaneously develope an SLE-like autoimmune disease [58] and glomerulonephritis. The Fas-mediated apoptosis defect is believed to contribute to the autoimmune disease due to the failure in induced cell death of activated $T$ cells. Morito et al. [59] generated $N r f 2^{-/-} l p r / l p r$ by crossing $N r f 2^{-/-}$on the ICR background strain with MRL/lpr mice. Surprisingly, Nrf2 deficiency prolonged the lifespan of female mice as $50 \%$ of them lived twice as long. Since renal failure is the leading cause of death in the MRL/lpr lupus model, the prolonged lifespan is likely due to improved renal function shown by the normalization of serum creatinine and BUN, reduced proteinuria, and improved nephritis. Nrf $2^{-1-} l p r / l p r$ mice had lower serum IgG and anti-dsDNA and lymphadenopathy scores. The number of apoptotic cells increased in the kidneys and spleen of $\mathrm{Nrf2} 2^{-/}$lpr/lpr mice, and the survival of splenocytes from these mice in response to TNF $\alpha$ was reduced. Spleen-cell apoptosis and TNF $\alpha$-induced splenocyte cell death were improved by administering glutathione to mice or to a culture of harvested splenocytes. The findings suggest that loss of Nrf2 enhanced apoptosis, which in turn abrogated abnormal apoptosis resulting from the $l p r$ gene mutation in this lupus model. However, these effects of Nrf2 loss were not observed when $\mathrm{Nrf}^{-/-}$mice developed on the $\mathrm{C} 57 \mathrm{Bl} / 6$ background strain, B6.Nrf2 ${ }^{-/}$, were crossed with the B6/lpr mouse model of lupus [60]. The B6/lpr mice had the same spontaneous Fas mutation, but on the C57Bl/ 6 mouse background strain, and rarely developed nephritis [47]. In the crossed B6.Nrf $2^{-1-} l p r / l p r$ mice, earlystage nephritis increased, and this was associated with Th17 activation and an increase in Th17 relevant cytokines (Il17, Il17f, Il23, Il23r, and Roryt), suggesting a role for Nrf2 prevention of Th17 differentiation and function in LN.

The differences in outcome with Nrf2 deficiency in these two studies were likely due to the background strain of the mice used, as disease onset and the degree of tissue lesions associated with Fas ${ }^{l p r}$ mutation are strain dependent [47,61]. This mutation on the C57Bl/ 6 strain causes significantly lower levels of anti-dsDNA antibodies and lymphoproliferation compared to this mutation on the MRL/MpJ mice, which have much higher levels of these parameters, develope the highest amount of renal lesions, and have half the lifespan. These studies suggested that Nrf2 may play a role in resistance to disease in B6/lpr mice, and Nrf2 deficiency in B6.Nrf2 ${ }^{-/} l p r / l p r$ mice may make these mice more susceptible to injury. Furthermore, the basal Nrf2 signaling axis and gene-target expression may be different in MRL/lpr and B6/lpr mice, and Nrf2 function may be temporally regulated in these SLE models. Thus, the specific roles of Nrf2 in different stages of the disease and the specific cell types in SLE remain to be defined.

\subsubsection{Nrf2 is Regulated in Experimental Models of SLE}

Nrf2 expression or activity was regulated in different tissues during experimental models of SLE (Table 2). Intraperitoneal injection of mice with pristane $(2,6,10,14$ tetramethylpentadecane) causes SLE-like disease with autoantibodies and immune complex glomerulonephritis [62]. Glomerulonephritis typically develops months after administration of pristane. In Balb/c mice, renal Nrf2 protein abundance and expression of one of its transcriptional targets, HO-1, decreased, while NFkB expression or activation increased [63-65] following 6-7 months of pristane-induced lupus. 
Table 2. Regulation of Nrf2 in Animal Models of SLE.

\begin{tabular}{|c|c|c|c|c|}
\hline Model of SLE & & & & \\
\hline $\begin{array}{c}\text { Duration } \\
\text { (Mouse Strain) }\end{array}$ & Tissue/Cells & $\begin{array}{c}\text { Effect on } \\
\text { Nrf2/Nrf2 Targets }\end{array}$ & Other Pathways & Refs. \\
\hline $\begin{array}{l}\text { Pristane } \\
1-2 \text { weeks } \\
\text { (C57BL/6) }\end{array}$ & $\begin{array}{l}\text { peritoneal } \\
\text { exudate } \\
\text { macrophages }\end{array}$ & $\begin{array}{l}\downarrow N r f 2, \text { Gpx } 4, \operatorname{Prdx} 1 \\
\text { Gclc, Nqo1, Sod2, } \\
\text { Gsr, Srxn gene } \\
\text { expression } \\
\downarrow N r f 2 \text { binding to } \\
\text { ARE-motif }\end{array}$ & $\begin{array}{c}\downarrow \text { HSP70 protein } \\
\uparrow \text { mitochondrial superoxide }\end{array}$ & Han et al. [48] \\
\hline $\begin{array}{l}5 \text { months } \\
(\mathrm{Balb} / \mathrm{c})\end{array}$ & kidney & $\begin{array}{l}\leftrightarrow_{\text {HO-1 protein }} \\
\leftrightarrow_{\text {Nqo1 mRNA }}\end{array}$ & $\uparrow \mathrm{MCP1}$ protein & Ebihara et al. [66] \\
\hline $\begin{array}{l}5.5 \text { months } \\
7 \text { months } \\
\text { (C57B/SV129) }\end{array}$ & $\begin{array}{l}\text { Kidney } \\
\text { kidney }\end{array}$ & $\begin{array}{l}\uparrow \mathrm{Nrf2}, \mathrm{NQO} 1 \text { protein } \\
\uparrow \mathrm{Nrf2} \text {, NQO1 protein }\end{array}$ & $\begin{array}{c}\uparrow i \text { Nos, } T g f b 1, N q 01, F n \text { mRNA } \\
\uparrow i N o s, F n \text { mRNA; } \uparrow \text { p-NFkB-p65 }\end{array}$ & Jiang et al. [16] \\
\hline $\begin{array}{l}6 \text { months } \\
(\text { Balb/c) }\end{array}$ & Kidney & $\downarrow N r f 2, \mathrm{HO}-1$ protein & $\begin{array}{c}\uparrow \text { NFkB-p65, p-STAT3 } \\
\uparrow p-p 38, \text { p-JNK, p-ERK } \\
\uparrow i N O S ; \uparrow m P G E S-1, \text { PGE2 } \\
\uparrow N L R P 3, \text { IL-1 } \beta, \text { IL-18 }\end{array}$ & Castejon et al. [63] \\
\hline $\begin{array}{l}6 \text { months } \\
(\text { Balb/c) }\end{array}$ & Kidney & $\downarrow N r f 2, \mathrm{HO}-1$ protein & $\begin{array}{c}\downarrow \text { IkB } \alpha ; \uparrow p-S T A T 3 \\
\uparrow \mathrm{mPGES}-1, \text { PGE2 } \\
\uparrow \mathrm{p}-\mathrm{p} 38, \mathrm{p}-\mathrm{JNK}, \mathrm{p}-\mathrm{ERK}\end{array}$ & $\begin{array}{c}\text { Aparicio- } \\
\text { Soto et al. [65] }\end{array}$ \\
\hline $\begin{array}{l}7 \text { months } \\
(\text { Balb/c) }\end{array}$ & Kidney & $\begin{array}{l}\downarrow \text { nuclear Nrf2 } \\
\downarrow \text { HO-1 protein }\end{array}$ & $\begin{array}{c}\uparrow \mathrm{p}-\mathrm{NF} \kappa \mathrm{B} ; \\
\uparrow \mathrm{NLRP3} \text {, cleaved casp1, IL-1 } \beta \\
\uparrow R O S, \text { GPx activity }\end{array}$ & Li et al. [64] \\
\hline $\begin{array}{l}7 \text { months } \\
(\text { Balb/c) }\end{array}$ & $\begin{array}{l}\text { MDSC } \\
\text { (spleen) }\end{array}$ & $\begin{array}{l}\downarrow \text { nuclear Nrf2 } \\
\leftrightarrow{ }_{\text {HO-1 protein }}\end{array}$ & $\begin{array}{c}\uparrow I l 1 b, \text { Il6, Il8, Tnfa mRNA } \\
\uparrow \text { senescence markers (p21, } \\
\text { p53, p21) } \\
\uparrow i N O S, \text { p47phox }\end{array}$ & Li et al. [67] \\
\hline $\begin{array}{c}A S L N \\
5 \text { weeks } \\
\text { (NZB/NZW) }\end{array}$ & kidney & $\downarrow$ nuclear Nrf2 & $\uparrow$ IL-6, p47phox; $\uparrow$ GPx activity & Tsai et al. [68] \\
\hline $\begin{array}{c}5 \text { weeks } \\
(\mathrm{NZB} / \mathrm{NZW})\end{array}$ & kidney & $\downarrow$ nuclear Nrf2 & $\begin{array}{c}\uparrow N L R P 3, \text { IL-1 } \beta \\
\uparrow p 47 \text { phox, COX-2, PGE2 }\end{array}$ & Ka et al. [69] \\
\hline $\begin{array}{l}\text { NZB/W F1 } \\
8.5 \text { months }\end{array}$ & kidney & $\begin{array}{c}\downarrow \text { nuclear Nrf2 } \\
\downarrow \text { Ho1, Nqo1 mRNA }\end{array}$ & $\begin{array}{c}\uparrow p 47 \text { phox; } \uparrow \text { GPx activity } \\
\uparrow N L R P 3, \text { IL-1 } \beta \text {, cleaved casp1 }\end{array}$ & Tsai et al. [70] \\
\hline $\begin{array}{l}\text { BPA exposure } \\
6 \text { weeks } \\
\text { (MRL/lpr) }\end{array}$ & kidney & $\downarrow N r f 2$ protein & $\begin{array}{c}\uparrow \mathrm{NFkB}-\mathrm{p} 65 ; \downarrow \text { mTOR } \\
\text { Abnormal autophagy signaling } \\
\uparrow \mathrm{ER} \alpha \text { and AhR expression }\end{array}$ & Dong et al. [71] \\
\hline $\begin{array}{l}\text { TCE-induced } \\
6 \text { months }\end{array}$ & liver & $\leftrightarrow_{\mathrm{Nrf2}}$ protein & $\leftrightarrow_{\mathrm{NFkB}, \mathrm{iNOS}}$ & Banerjee et al. [72] \\
\hline $\begin{array}{l}13 \text { months } \\
\text { (MRL/MpJ) }\end{array}$ & & $\downarrow N r f 2$ protein & $\begin{array}{c}\leftrightarrow_{\text {p-p38, p-JNK, p-ERK }} \\
\uparrow N F k B, \text { iNOS } \\
\uparrow \mathrm{p}-\mathrm{p} 38, \mathrm{p} \text {-JNK, p-ERK } \\
\uparrow \mathrm{IL}-12 \text { protein and mRNA } \\
\uparrow \text { protein carbonyls } \\
\uparrow N F \kappa B, \text { iNOS } \\
\uparrow \mathrm{p}-\mathrm{p} 38, \mathrm{p} \text {-JNK, p-ERK } \\
\uparrow \mathrm{IL}-12, \mathrm{TNF}, \mathrm{RANTS} \text { protein } \\
\uparrow I l 12, \text { Rantes mRNA } \\
\uparrow \text { protein carbonyls }\end{array}$ & \\
\hline
\end{tabular}

Abbreviations: Gpx, glutathione peroxidase; Prdx, peroxiredoxin; ARE, Antioxidant response element; HO-1, Heme Oxygenase-1; NQO1, NAD(P)H Quinone Dehydrogenase 1; sod-superoxide dismutase GCLC-GlutamateCysteine Ligase Catalytic Subunit; Gsr-Glutathione Disulfide Reductase; srxn-Sulfiredoxin; HSP70-heat shock protein70; MCP1-monocyte chemoattractant protein-1; iNOS- inducible nitric oxide synthase; TGF $\beta$-transforming growth factor $\beta$; FN-fibronectin STAT3-signal transducer and activator 3; p-p38-phospho p38 mitogen activated kinase (MAPK); p-JNK-phospho c-Jun N-terminal kinase; p-ERK-phospho extracellular signal-regulated kinase; mPGES1-Microsomal prostaglandin E synthase-1; PGE2-prostaglandin E2; IL-1-interleukin 1; NLRP3-NOD-, LRR- and pyrin domain-containing protein 3; casp-caspase; ROS-reactive oxygen species; TNF-tumor necrosis factor; COX-2-cyclooxygenase 2; ER $\alpha$-estrogen receptor $\alpha$; AhR-arylhydrocarbon receptor; RANTES-Regulated on Activation, Normal T Cell Expressed and Secreted; NFkB-Nuclear Factor kappa-light-chain-enhancer of activated B cells; IкB-inhibitor of nuclear factor kappa B. $\downarrow$, decreased; $\uparrow$, increased; $\leftrightarrow$, not changed or, not different. 
One study found no change in the expression of Nrf2 gene targets HO-1 and NQO1 [66]. MDSCs isolated from the spleen of pristane-treated mice showed decreased Nrf2 nuclear localization and accumulation in the cytosol [67]. In a separate study, transcript levels for Nrf2 and two of its transcriptional targets, and Nrf2 binding activity to consensus ARE sites, decreased in macrophages 2 weeks after pristane injection. In addition, Nrf2 expression was higher in non-classic (pro-resolving) macrophages compared to classic (pro-inflammatory) macrophages [48]. In the same study, pristane caused higher surface expression of IFNregulated proteins Ly-6C and PDCA-1 and interferon-stimulated gene expression of $M x 1$, Isg15, and Irf7 in the peritoneal exudate cells from $\mathrm{Nrf2}^{-/-}$mice. Combined, these studies demonstrated downregulation of the Nrf2 pathway in kidneys, MDSCs from spleen, and macrophages during pristane-induced SLE and highlighted the role of Nrf2 inhibition of interferon signaling. Alternatively, in a separate study, Jiang et al. showed increased protein abundance of Nrf2 and its target NQO1 in kidneys following 5.5 months of pristane injection [16]. The difference in renal Nrf2 protein abundance in this and former studies may be due to differences in the background strain of the mice (See Table 2). Furthermore, the study by Jiang et al. also showed pristane-induced lupus nephritis to be more severe in Nrf2 $2^{-/-}$mice, which were associated with increases in transforming growth factor $\beta 1$, fibronectin, and iNOS.

The role of Nrf2 was evaluated in murine models of accelerated severe LN (ASLN). One ASLN model was developed with a twice-weekly intraperitoneal LPS injection into female NZB/W F1 lupus-prone mice. By five weeks, these mice show increased proteinuria and serum BUN and creatinine, and decreased Nrf2 protein abundance $[68,69]$. Nrf2 protein abundance also decreased in NZB/W F1 lupus-prone mice not injected with LPS [70].

Environmental toxins can cause dysregulated immune responses. The contaminant trichloroethene (TCE) and its metabolites caused autoimmune/SLE-like disease in MRL/MpJ mice [71]. This model exhibited increased anti-dsDNA antibodies and increased liver protein carbonyls indicative of protein oxidation. The livers of these mice had increased inflammation as shown by the induction of transcript and protein levels of p65 NFkB, TNF $\alpha$, IL-12, and RANTES. Alternatively, Nrf2 transcript and protein abundance decreased [71]. Exposure of lupus-prone MRL/lpr mice to another environmental toxin, bisphenol A (BPA), increased autoantibodies, proteinuria, and caused more severe nephritis, which was attributed to aberrant autophagy and decreased Nrf2 expression [72].

These studies clearly showed that inflammation and oxidative stress in mouse models of SLE are associated with reduced Nrf2 protein abundance and transcriptional activation. Therefore, mechanisms to restore Nrf2 abundance and activity are promising for the treatment of SLE.

\subsection{Nrf2 in Human SLE and LN}

Multiple studies have shown increased levels of oxidative stress in the blood, tissues, and immune cells of SLE patients [16,73-75]. Furthermore, levels of oxidative stress correlate with disease activity. The Keap1/Nrf2 pathway is a vital signaling pathway for antioxidant defense; thus, Nrf2 levels typically increase in response to oxidative stress, which, if left unchecked, oxidative stress can contribute to increased apoptosis, poor clearance of apoptotic bodies, autoantibody production, and increased tissue damage [6,10]. Studies involving human SLE and LN are primarily observational, but they suggest that that Nrf2 activity is impaired, which may contribute to increased oxidative stress in SLE patients. 


\subsubsection{Nrf2 in Human Kidneys and Whole Blood}

The glomeruli of patients with LN have increased markers of oxidative stress and increased Nrf2 activation [16]. Interestingly, the level of Nrf2 did not correspond with disease severity as the glomeruli from patients with class III (focal proliferative) LN had higher levels of Nrf2 compared to those with class IV (diffuse proliferative) LN [16]. Additionally, Nrf2 expression was increased in glomeruli from other immune-mediated kidney diseases, including IgA nephropathy [16]. While Nrf2 expression was elevated in tissue, whole blood from SLE patients demonstrated lower levels of Nrf2 and SOD2 compared to healthy controls, suggesting impaired clearance of ROS [48].

\subsubsection{Nrf2 in Human Dendritic Cells}

Plasmacytoid dendritic cells (pDCs) isolated from SLE patients with high disease activity were found to have elevated intracellular ROS compared to cells in SLE patients in remission [74]. Furthermore, Nrf2 and Keap1 levels decreased in pDCs from patients with active SLE compared to healthy controls, suggesting that regulation of oxidative stress via the Keap1/Nrf2 pathway was impaired in pDCs in these patients [74], which may contribute to the pathogenic role of $\mathrm{pDC}$ in SLE.

\subsubsection{Nrf2 in Human T cells and NK Cells}

Tandon et al. evaluated oxidative stress, Keap1, and Nrf2 in T cell and Natural Killer (NK) cell subtypes isolated from SLE patients [75]. They found a positive correlation between SLE disease activity (as assessed by SLEDAI) and ROS in helper and cytotoxic T-cells. They also demonstrated a positive correlation between disease activity and Keap1 levels in $\mathrm{CD}^{+} \mathrm{CD}^{+} \mathrm{T}$ cells, $\mathrm{CD}^{+}{ }^{+} \mathrm{CD} 8^{+} \mathrm{T}$ cells, and $\mathrm{CD} 3^{-} \mathrm{CD} 56^{\text {bright }} \mathrm{NK}$ cells. They found a positive correlation between disease activity and protein expression of $\mathrm{Nrf} 2$ in $\mathrm{CD}^{+}{ }^{+} \mathrm{CD} 8^{+}$ $\mathrm{T}$ cells, but not with other cell types. SLE disease activity positively correlated with mRNA expression of Keap1 in $\mathrm{CD}^{+}, \mathrm{CD}^{+}$, and $\mathrm{CD} 56^{+}$cells and mRNA expression of $\mathrm{Nrf} 2$ in $\mathrm{CD} 8^{+}$cells [75]. The biologic effects of Keap1 and Nrf2 regulation in these cell subtypes during SLE remains to be determined.

\subsubsection{Nrf2 and Antioxidative Gene Polymorphisms Associated with SLE}

Numerous gene polymorphisms that regulate genes involved in oxidative stress pathways have been identified in SLE: superoxide dismutase $(S O D)$ [76], glutathione peroxidase (GPx) [76], catalase (CAT) [76,77], and a component of NADPH oxidase, NCF2 [78]. Nrf2 polymorphisms are associated with LN in females with pediatric-onset SLE in a Mexican Mestizo population [79]. However, a separate study failed to show a relationship between Nrf2 polymorphisms and SLE in a Japanese population. The latter study also had a limited sample size of 51 SLE patients [80]. An integrative biology approach identified transcriptional networks, including the Nrf2 pathway, associated with CKD after evaluating 16 CKD gene loci detected in a meta-analysis of multiple GWAS studies involving 66,093 subjects [81].

\section{Nrf2 Inducers}

The promising role of Nrf2 activation to combat oxidative and inflammatory stress resulted in the investigation of a large number of Nrf- inducing compounds in vitro (using cell culture studies), in animal studies (using healthy and disease models), and in healthy human subjects or some disease states. The majority of the inducers were electrophilic and reacted with cysteine sulfhydryl groups on Keap1. Mass spectrometric and sitedirected mutagenesis approaches identified specific cysteine residues on Keap1 modified in response to, and required for, activation of $\mathrm{Nrf2}[82,83]$. Three specific cysteine residues on Keap1 include Cys-151, Cys-273, and Cys-288 and are believed to be the main sensors for electrophilic inducers of Nrf2 [84]. These residues may be modified individually in combination in response to various inducers. 
Nrf2 inducers can generally be divided into 5 classes based on one or more Keap1 cysteine residues with which they modify [85]). Class I electrophilic inducers prefer Cys-151 and include tert-butylhydroquinone, diethyl maleate, dimethyl fumarate (DMF), sulforaphane (SFN), nitric oxide, CDDO (2-cyano-3,12-dioxooleana-1,9(11)-dien-28-oic acid), CDDO-Im (Imidazole) and CDDO-Me (methyl ester; or bardoxolone methyl). Class II electrophilic inducers prefer Cys-288 and include 15d-PGJ2, 15-deoxy-12,14-prostaglandin J2. Class III electrophilic inducers modify Cys-151/Cys-273/Cys-288 residues and include nitrooctadec-9-enoic acid, 4-hydroxynonenal, and sodium arsenate. Class IV inducers are electrophilic and Cys-151/Cys-273/Cys-288-independent and include Nrf2 induction in response to hydrogen peroxide, prostaglandin A2, dexamethasone 21-mesylate. Keap1 cysteine residues Cys-434, Cys-266, and Cys-613 are also thought to be important for Nrf2 activation [86].

Class V Nrf2 inducers represent non-electrophilic inducers such as compounds or peptides inhibiting Keap1/Nrf2 association [87]) that effectively lead to Nrf2 induction [88,89]. In addition, endogenous protein interactions capable of disrupting Keap1/Nrf2 association and Nrf2 degradation exist, such as p21 interaction with Nrf2 [90] and p62/SQSTM association with Keap1 [91].

\subsection{Nrf2 Inducers in Animal Models of SLE}

A number of studies have investigated Nrf2-inducing compounds in mouse models of SLE. These studies highlighted the therapeutic potential of Nrf2 activation for decreasing oxidative stress and inflammation and limiting SLE progression (Table 3).

Table 3. Effect of Nrf2 Inducers in Animal Models of SLE.

\begin{tabular}{|c|c|c|c|}
\hline Nrf2 Inducer & Model of SLE & Effects & Ref \\
\hline \multirow[t]{2}{*}{ Sulforaphane } & TCE-induced & $\begin{array}{c}\downarrow \text { p38 and ERK MAPK phosphorylation } \\
\downarrow \text { Tnfa and Il12 mRNA }\end{array}$ & Banerjee et al. [71] \\
\hline & Pristane-induced & $\begin{array}{l}\downarrow \text { albuminuria } \\
\text { Augmented renal Nrf2 and NQO1 } \\
\text { protein abundance }\end{array}$ & Jiang et al. [16] \\
\hline $\begin{array}{l}\text { Dimethyl } \\
\text { Fumarate }\end{array}$ & Pristane-induced & 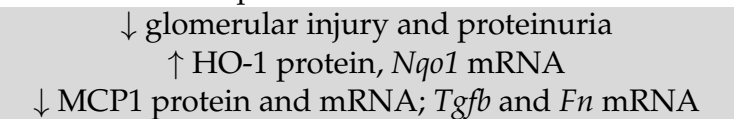 & Ebihara et al. [66] \\
\hline CDDO-Im & Pristane-induced & $\begin{array}{c}\downarrow \text { classic macrophages in B6 mice } \\
\downarrow \text { mitochondrial superoxide in macrophages } \\
\downarrow \text { macrophage Ifnar } 1 \text { and IFN-stimulated } \\
\text { gene expression }\end{array}$ & Han et al. [48] \\
\hline Baicalein & Pristane-induced & $\begin{array}{c}\downarrow \text { anti-dsDNA antibodies, proteinuria, renal injury } \\
\downarrow \text { serum IL-1B and IL-18, and renal oxidative stress } \\
\uparrow \text { Renal Nrf2 and HO-1 and phospho-NFkB } \\
\text { and NLRP3 } \\
\downarrow \text { MDSCs in kidney, spleen, bone marrow, } \\
\text { and PBMCs }\end{array}$ & Li et al. [64] \\
\hline Extra virgin olive oil & Pristane-induced & $\begin{array}{c}\text { restored serum MMP3, renal Nrf2 and } \\
\text { HO-1 abundance } \\
\text { attenuated renal p38, ERK, and JNK } \\
\text { phosphorylation } \\
\downarrow \text { LPS-induced TNF } \alpha \text {, IL-6, IL-10, and IL-17 } \\
\text { in splenocytes }\end{array}$ & $\begin{array}{l}\text { Aparicio-Soto } \\
\text { et al. [65] }\end{array}$ \\
\hline Oleuropein & Pristane-induced & $\downarrow$ inflammatory markers and renal injury, Nrf2 & Castejon et al. [63] \\
\hline \multirow[t]{2}{*}{$\begin{array}{l}\text { Dihydro- } \\
\text { artemisinin }\end{array}$} & Pristane-induced & inhibit MDSC senescence & Li et al. [67] \\
\hline & BXSB mice & $\begin{array}{l}\downarrow \text { serum and macrophage secretion of TNF } \alpha ; \\
\text { renal NFKB }\end{array}$ & Li et al. [92] \\
\hline Artemisinin & $\begin{array}{l}\text { chronic graft } \\
\text { vs. host disease }\end{array}$ & $\downarrow$ proteinuria; $\downarrow$ inflammatory, pro-fibrotic mediators & Wu et al. [93] \\
\hline
\end{tabular}


Table 3. Cont.

\begin{tabular}{|c|c|c|c|}
\hline Nrf2 Inducer & Model of SLE & Effects & Ref \\
\hline \multirow[t]{2}{*}{ Artesunate } & \multirow[t]{2}{*}{$\mathrm{MRL} / \mathrm{lpr}$} & $\begin{array}{c}\downarrow \text { anti-dsDNA; } \downarrow \text { proteinuria; improved } \\
\text { kidney function }\end{array}$ & Jin et al. [94] \\
\hline & & $\downarrow$ renal Il6, Ifn, and Il21 mRNA & Dang et al. [95] \\
\hline \multirow[t]{2}{*}{ SM934 } & \multirow[t]{2}{*}{$\mathrm{MRL} / \mathrm{lpr}$} & 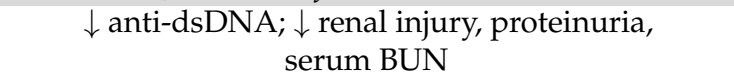 & Hou et al. [96] \\
\hline & & $\downarrow$ IL-6, Il-10, Il-12, activated B cells and plasma cells & Wu et al. [97] \\
\hline Antroquinonol & ASLN mice & $\begin{array}{c}\downarrow \text { proteinuria, hematuria, kidney injury } \\
\text { improve kidney function } \\
\uparrow \text { Nrf2 activity and } \downarrow \text { ROS in kidney }\end{array}$ & Tsai et al. [68] \\
\hline Citral & ASLN mice & $\begin{array}{l}\downarrow \text { proteinuria, renal injury; improved } \\
\text { kidney function } \\
\uparrow \text { Nrf2 activity; } \downarrow \text { ROS and NLRP3 inflammasome }\end{array}$ & Ka et al. [69] \\
\hline EGCG & NZB/W F1 mice & $\begin{array}{l}\downarrow \text { proteinuria, serum BUN and creatinine, } \\
\text { and nephritis } \\
\text { unaltered glomerular IgG deposition or anti-dsDNA } \\
\text { restored Nrf2 protein, Nqo1 and Ho1 mRNA } \\
\downarrow \text { inflammasome markers }\end{array}$ & Tsai et al. [70] \\
\hline
\end{tabular}

Abbreviations: EGCG-Epigallocatechin-3-gallate; p38-p38 mitogen activated protein kinase; TNF-tumor necrosis factor; IL-12-interleukin 12; HO-1, Heme Oxygenase-1; NQO1, NAD(P)H Dehydrogenase Quinone 1; MCP1monocyte chemoattractant protein-1; TGF $\beta$-transforming growth factor $\beta$; FN-fibronectin; IFN-interferon; NFKBNuclear Factor kappa-light-chain-enhancer of activated B cells; NLRP3-NOD, LRR and pyrin domain-containing protein 3; MDSC-Myeloid-derived suppressor cells; PBMC-peripheral blood mononuclear cell; JNK-c-Jun N-terminal kinase; LPS-lipopolysaccharide; ROS-reactive oxygen species; BUN-Blood Urea Nitrogen; TCEtrichloroethene; ASLN-accelerated severe lupus nephritis; ERK-extracellular signal-regulated kinase. $\downarrow$, decreased; $\uparrow$, increased.

\subsubsection{Sulforaphane}

Sulforaphane (SFN) is an isothiocyanate compound found in cruciferous vegetables such as broccoli and cabbage. It is produced from the hydrolysis of its precursor, glucoraphanin, after coming into contact and interacting with myrosinase when the plant's structures are damaged. SFN is one the most widely studied Nrf2 inducing compounds in animal disease models and clinical studies [98]. In pristane-induced SLE, SFN decreased albuminuria and augmented renal cortical Nrf2 and NQO1 protein abundance increased by pristane [16]. In the TCE model of autoimmune/SLE-like disease, SFN decreased TCE-induced p38 and ERK MAPK phosphorylation as well as Tnfa and Il12 mRNA [71].

\subsubsection{Dimethyl Fumarate}

Dimethyl Fumarate (DMF) is a fumaric acid ester currently used as the FDA-approved drug Tecfidera to treat multiple sclerosis [99]. In pristane-induced SLE, DMF decreased glomerular injury and proteinuria [66]. Furthermore, DMF increased the renal protein levels of the Nrf2 targets HO-1 and the mRNA levels of Nqo1, but decreased renal MCP1 proteins, and Mcp1, Il6, Tgfb, and Fn mRNA levels. These findings showed that DMF decreased pristane-induced LN through the induction of Nrf2 and attenuation of pro-inflammatory and pro-fibrotic signaling.

\subsubsection{CDDO (2-Cyano-3,12-dioxooleana-1,9(11)-dien-28-oic Acid)}

CDDO-Im (Imidazole) and CDDO-Me (methyl ester; or bardoxolone methyl) are synthetic oleanane triterpenoids such as oleanolic acid, synthesized in plants by the cyclization of squalene. Bardoxolone methyl has been used in preclinical and clinical studies to treat cancer $[100,101]$ and diabetic kidney disease [102]. At nanomolar concentrations, these compounds are strong inducers of Nrf2 and promote cytoprotection, whereas at higher concentrations they activate the NFKB pathway and apoptosis [101]. In pristane-induced SLE, CDDO-Im decreased classic (pro-inflammatory) macrophages (CMs) and showed an increasing trend for pro-resolving non-classic macrophages (NCMs). This effect of CDDO-Im occurred only in B6 mice, whereas it did not alter CMs or NCMs in Balb/c 
mice [48]. Additionally, CDDO-Im decreased mitochondrial superoxide in CMs and NCMs of pristane-treated mice, and decreased Ifnar 1 gene expression and IFN-stimulated gene expression in macrophages.

\subsubsection{Epigallocatechin-3-Gallate (EGCG)}

EGCG is a bioactive polyphenol from green tea and a known Nrf2 inducer [103]. Its role in lupus nephritis was examined in NZB/W F1 mice where it reduced proteinuria, serum BUN and creatinine, and nephritis without altering glomerular IgG deposition or anti-dsDNA [70]. In addition, EGCG restored Nrf2 protein expression and transcript levels of two of its gene targets, Nqo1 and Ho1, while decreasing the markers of inflammasomes.

\subsubsection{Artemisinin Derivatives}

There is a long history in traditional Chinese holistic medicine of using Artemisia annua to treat malaria [104]. Artemisinin and its derivatives Artesunate, dihydroartemisinin, and SM934, are known to induce Nrf2 [105-108] and have been used in studies of rheumatic diseases, including SLE. In pristane-induced SLE, dihydroartemisinin inhibited MDSC senescence in an Nrf2-dependent manner [67]. In the BXSB mouse strain that spontaneously developed an autoimmune/SLE-like disease, dihydroartemisinin decreased TNF $\alpha$ in the serum and secretion from peritoneal macrophages and decreased renal p65 subunit of NFkB [92]. In a chronic graft-vs-host disease model of lupus nephritis [109], Artemisinin decreased proteinuria and inflammatory and pro-fibrotic mediators [93]. In lupus-prone MRL/lpr mice, Artesunate decreased serum anti-dsDNA [94], improved renal function, and decreased renal injury and proteinuria along with renal Il6, Ifn, and Il21 mRNA [95]. In MRL/lpr lupus-prone mice, another derivative, SM934, increased survival, decreased IL-6, IL-10, IL-12, and activated B cells and plasma cells [97], and lowered proteinuria, renal injury, BUN, and serum anti-dsDNA antibodies [96].

\subsubsection{Baicalein}

Baicalein is a flavonoid from Scutellaria baicalensis Georgi roots, a traditional Chinese medicine known to combat oxidative stress partly by Nrf2 activation [64]. In pristaneinduced SLE, Baicalein reduced anti-dsDNA antibodies, proteinuria, renal injury, serum cytokines (IL-1B and IL-18), and renal oxidative stress. Renal Nrf2 and HO-1 abundance increased while NFKB phosphorylation and NLRP3 were downregulated. In addition, Baicalein decreased the percentages of MDSCs in kidney, spleen, bone marrow, and peripheral blood mononuclear cells. In vitro treatment of MDSC with a specific Nrf2 inhibitor, brusatol, abolished the protective effects of Baicalein on oxidative stress and inflammation in LPS-primed MDSCs, suggesting the effects of Baicalein were Nrf2 dependent.

\subsubsection{Dietary Extra Virgin Olive Oil (EVOO)}

Feeding mice EVOO reversed pristane-induced the SLE effects on increased serum matrix metalloproteinase 3 and decreased renal Nrf2 and HO-1 abundance. In addition, dietary EVOO attenuated pristane induction of renal p38, ERK, and JNK phosphorylation. Furthermore, EVOO decreased the production of pro-inflammatory cytokines (TNF $\alpha$, IL-6, IL-10, and IL-17) in LPS-stimulated splenocytes from pristane-treated mice [65].

\subsubsection{Oleuropein}

Pristane-treated mice fed oleuropein (an antioxidant derivative of olive leaf extract) had increased Nrf2 activation, decreased inflammatory markers, and attenuated kidney damage [63].

\subsubsection{Antroquinonol}

Antroquinonol, an antioxidant derived from Antrodia camphorate, was explored in ASLN mice [68]. In this model, mice treated with antroquinonol beginning 2 days after the first dose of LPS, had significantly attenuated disease. Findings included decreased pro- 
teinuria, hematuria, improved kidney function, and attenuation of severe histopathologic features including cellular crescent formation, neutrophil infiltration and fibrinoid necrosis. Antroquinonol prevented ROS production and increased Nrf2 activation in the kidney.

\subsubsection{Citral}

The effects of Citral, an anti-oxidant found in Litsea cubeba, was investigated in ASLN mice [69]. It decreased proteinuria, improved kidney function, and attenuated histopathological features including reduction in cellular crescents. Citral inhibited NLRP3 inflammasome activation, decreased ROS, and enhanced Nrf2 activation.

\subsection{Nrf2 Inducers in Studies of Cells from SLE Patients}

\subsubsection{Artesunate}

Artesunate was explored in the regulation of macrophage migration inhibitory factor (MIF) in SLE. MIF levels were increased in serum from SLE patients and positively associated with disease activity and accumulated damage in SLE PBMCs. Artesunate inhibited IFN-inducible genes (LY6E and ISG15) in SLE PBMCs and suppressed MIF production induced by IFN $\alpha-1 b$ stimulation [110].

\subsubsection{Octyl Itaconate (OI)}

OI is an Nrf2 inducer that causes Keap1/Nrf2 dissociation, Nrf2 protein accumulation, nuclear translocation, and target-gene induction in THP-1 human macrophages. It also activated Nrf2 in PBMCs from SLE patients. OI inhibited mRNA expression and production of TNF- $\alpha$, IL-1 $\beta$, and IL- 6 and NFKB activation in PBMCs, and LPS-activated THP-1 cells from SLE patients, and these effects were dependent on Nrf2 [111].

\subsection{Potential Utilization of Nrf2 Inducers for the Treatment of SLE in the Clinical Setting}

While many Nrf2-inducing compounds have been identified and investigated in preclinical studies, the use of these agents in clinical settings for therapeutic purposes has been limited. Currently, DMF (Tecfidera) has been approved by the United States Food and Drug Administration for the treatment of multiple sclerosis [99]. Similarly, Fumaderm, a drug that combines DMF with monoethyl fumarate salts, is used in Europe to treat plaque psoriasis [112]. Two studies have reported the use of fumaric acid esters for effective treatment of discoid lupus erythematosus [113,114] and severe chilblain lesions [114]. These findings, combined with the anti-inflammatory properties of DMF and its approval for treating other diseases associated with inflammation, place DMF at the forefront of autoimmune disease treatment.

Bardoxolone methyl or CDDO-Me exhibits potent antioxidative, anti-inflammatory, and anti-carcinogenic properties. Early studies in cancer patients treated with bardoxolone methyl observed decreases in serum creatinine, suggesting its use in treating chronic kidney disease (CKD). Early-phase clinical trials [115,116] and the more recent 2020 TSUBAKI [102] trial, showed promising results for the treatment of Type 2 diabetic patients with CKD. After the initial trials, clinical studies in the United States on late-stage CKD in type 2 diabetic patients were halted due to adverse events related to fluid overload and heart failure [117,118]. However, clinical trials for other forms of kidney disease such as, autosomal dominant polycystic kidney disease and Alport syndrome are currently being conducted (Clinicaltrials.gov; accessed 11/2021). A previous study identified shared transcriptional networks among 9 different forms of CKD, including lupus nephritis [81]. A network of 97 pathways were linked by shared genes and aggregated into clusters of inflammation and metabolic pathways centered on the Nrf2 pathway. Targeting Nrf2 for treatment of SLE and LN with bardoxolone methyl may be promising.

SFN is widely used in clinical studies, mostly in healthy subjects [119]. A lack of consistency in the various formulations used to examine its pharmacokinetics and pharmacodynamics may be responsible for hindering the use of SFN for therapeutic purposes. Formulations from broccoli have consisted of its precursor glucoraphanin, SFN, gluco- 
raphanin with myrosinase, broccoli or broccoli sprouts as raw/cooked/dried preparations, or extracts of broccoli seeds or sprouts.

Limitations to use of the three electrophilic Nrf2 inducers discussed thus far may be due to the non-specificity from modification of cysteine residues on proteins other than Keap1, leading to unintended responses or adverse events. Alternatively, complementary signaling events may be triggered to augment intended cytoprotective and therapeutic effects. Approaches with higher specificity may result from peptides or chemicals that disrupt Keap1/Nrf2 protein-protein interactions [87,88].

In addition, limitations to understanding downstream signaling and the potentially divergent effects of different Nrf2 inducers may hinder therapeutic uses in clinical settings. For example, studies in a mouse model of lung cancer by To et al., showed opposing effects on the size and number of tumors and differential induction of Nrf2 transcriptional gene targets in response to bardoxolone methyl, CDDO-Im, and DMF [120]. A recent review by Yagishita et al. [119] of Nrf2 biomarkers in clinical trials highlighted bardoxolone methyl, DMF, and SFN as Nrf2 inducers known to target Nrf2 in pre-clinical studies. Of these three compounds, SFN is the most widely studied compound with more than 75 published reports from clinical studies. Furthermore, compared to DMF and bardoxolone methyl, reports with SFN include more mechanism-based biomarkers measured in categories such as Nrf2 target genes, gene expression/function, inflammation, oxidative stress, carcinogen metabolites, and metabolomics. When comparing these categories among SFN, DMF, and bardoxolone methyl, studies examining Nrf2 target genes comprised around 20, 2.5, and $8 \%$ of the total publications for each inducer, respectively. Markers of inflammation were examined in $24,7.5$, and $16 \%$ of publications for SFN, DMF, and bardoxolone methyl, respectively, and for oxidative stress markers, 15,0 , and $0 \%$. Therefore, as previously shown by To et al. [120] defining cellular targets and downstream effects for different Nrf2 inducers in specific disease states, tissues, and cell types, is critical for achieving effective therapy without off-target or adverse effects in a clinical setting.

\section{Conclusions}

A critical role for Nrf2 in preventing SLE and autoimmune disorders by regulating redox homeostasis, inflammation, and immune responses, is apparent from numerous pre-clinical studies. These include development of an SLE-like autoimmune disorder and inflammation in Nrf2-deficient mice, downregulation of Nrf2 protein abundance and target gene expression in animal models of SLE, and the effects of Nrf2-inducing agents to combat oxidative and inflammation markers and SLE pathogenesis. These studies support previous reports on the role of oxidative stress in dysregulated immune responses and highlight the potential significance of antioxidative and drug metabolizing gene polymorphisms associated with SLE. Whether the beneficial effects of Nrf2 induction are indirectly related to the alleviation of stress or to the direct transcriptional regulation in immune cells remains to be defined. Furthermore, the beneficial and anti-inflammatory effects of Nrf2 activation may depend on the type of cell/tissue type and inflammation-associated disease. Targeting Nrf2 for therapeutic purposes is likely to be promising for the treatment of SLE. Defining cellular targets and downstream effects in response to different Nrf2-inducing agents in specific disease states, tissues, and cell types, is critical for the effective use of these compounds in a clinical setting.

Author Contributions: Conceptualization, M.T.B. and D.J.C.; methodology, not applicable/review article; software, not applicable/review article; validation, not applicable/review article; formal analysis, not applicable/review article; investigation, review of the literature, M.T.B. and D.J.C.; resources, not applicable/review article; data curation, not applicable/review article; writing-original draft preparation, M.T.B. and D.J.C.; writing—review and editing, M.T.B. and D.J.C.; visualization, M.T.B. and D.J.C.; supervision, M.T.B. and D.J.C.; project administration, M.T.B. and D.J.C.; funding acquisition, D.J.C. All authors have read and agreed to the published version of the manuscript.

Funding: D.J.C. received funding from the NIH (K08DK102542, R01DK126777). 
Conflicts of Interest: D.J.C. received speaking fees from GSK and Aurinia and consulting fees from Aurinia, Calliditas, Chinook, GSK, and Travere.

\section{References}

1. Tsokos, G.C. Systemic lupus erythematosus. N. Engl. J. Med. 2011, 365, 2110-2121. [CrossRef] [PubMed]

2. Almaani, S.; Meara, A.; Rovin, B.H. Update on Lupus Nephritis. Clin. J. Am. Soc. Nephrol. 2017, 12, 825-835. [CrossRef] [PubMed]

3. Bijl, M.; Reefman, E.; Horst, G.; Limburg, P.C.; Kallenberg, C.G. Reduced uptake of apoptotic cells by macrophages in systemic lupus erythematosus: Correlates with decreased serum levels of complement. Ann. Rheum. Dis. 2006, 65, 57-63. [CrossRef] [PubMed]

4. $\quad$ Labonte, A.C.; Kegerreis, B.; Geraci, N.S.; Bachali, P.; Madamanchi, S.; Robl, R.; Catalina, M.D.; Lipsky, P.E.; Grammer, A.C. Identification of alterations in macrophage activation associated with disease activity in systemic lupus erythematosus. PLoS ONE 2018, 13, e0208132. [CrossRef] [PubMed]

5. Herrada, A.A.; Escobedo, N.; Iruretagoyena, M.; Valenzuela, R.A.; Burgos, P.I.; Cuitino, L.; Llanos, C. Innate Immune Cells' Contribution to Systemic Lupus Erythematosus. Front. Immunol. 2019, 10, 772. [CrossRef]

6. Ohl, K.; Tenbrock, K. Oxidative Stress in SLE T Cells, Is NRF2 Really the Target to Treat? Front. Immunol. 2021, 12, 633845. [CrossRef]

7. Bomback, A.S.; Appel, G.B. Updates on the treatment of lupus nephritis. J. Am. Soc. Nephrol. 2010, 21, 2028-2035. [CrossRef]

8. Davidson, J.E.; Fu, Q.; Ji, B.; Rao, S.; Roth, D.; Magder, L.S.; Petri, M. Renal Remission Status and Longterm Renal Survival in Patients with Lupus Nephritis: A Retrospective Cohort Analysis. J. Rheumatol. 2018, 45, 671-677. [CrossRef]

9. Hamanaka, R.B.; Chandel, N.S. Mitochondrial reactive oxygen species regulate cellular signaling and dictate biological outcomes. Trends Biochem. Sci. 2010, 35, 505-513. [CrossRef]

10. Perl, A. Oxidative stress in the pathology and treatment of systemic lupus erythematosus. Nat. Rev. Rheumatol. 2013, 9, 674-686. [CrossRef]

11. Bona, N.; Pezzarini, E.; Balbi, B.; Daniele, S.M.; Rossi, M.F.; Monje, A.L.; Basiglio, C.L.; Pelusa, H.F.; Arriaga, S.M.M. Oxidative stress, inflammation and disease activity biomarkers in lupus nephropathy. Lupus 2020, 29, 311-323. [CrossRef] [PubMed]

12. Mittal, M.; Siddiqui, M.R.; Tran, K.; Reddy, S.P.; Malik, A.B. Reactive oxygen species in inflammation and tissue injury. Antioxid. Redox Signal. 2014, 20, 1126-1167. [CrossRef] [PubMed]

13. Kienhofer, D.; Boeltz, S.; Hoffmann, M.H. Reactive oxygen homeostasis - the balance for preventing autoimmunity. Lupus 2016, 25, 943-954. [CrossRef] [PubMed]

14. Zhao, J.; Ma, J.; Deng, Y.; Kelly, J.A.; Kim, K.; Bang, S.Y.; Lee, H.S.; Li, Q.Z.; Wakeland, E.K.; Qiu, R.; et al. A missense variant in NCF1 is associated with susceptibility to multiple autoimmune diseases. Nat. Genet. 2017, 49, 433-437. [CrossRef] [PubMed]

15. Yoh, K.; Itoh, K.; Enomoto, A.; Hirayama, A.; Yamaguchi, N.; Kobayashi, M.; Morito, N.; Koyama, A.; Yamamoto, M.; Takahashi, S. Nrf2-deficient female mice develop lupus-like autoimmune nephritis. Kidney Int. 2001, 60, 1343-1353. [CrossRef] [PubMed]

16. Jiang, T.; Tian, F.; Zheng, H.; Whitman, S.A.; Lin, Y.; Zhang, Z.; Zhang, N.; Zhang, D.D. Nrf2 suppresses lupus nephritis through inhibition of oxidative injury and the NF-kB-mediated inflammatory response. Kidney Int. 2014, 85, 333-343. [CrossRef] [PubMed]

17. Hayes, J.D.; Dinkova-Kostova, A.T. The Nrf2 regulatory network provides an interface between redox and intermediary metabolism. Trends Biochem. Sci. 2014, 39, 199-218. [CrossRef]

18. Otsuki, A.; Suzuki, M.; Katsuoka, F.; Tsuchida, K.; Suda, H.; Morita, M.; Shimizu, R.; Yamamoto, M. Unique cistrome defined as CsMBE is strictly required for Nrf2-sMaf heterodimer function in cytoprotection. Free Radic. Biol. Med. 2016, 91, 45-57. [CrossRef]

19. Chorley, B.N.; Campbell, M.R.; Wang, X.; Karaca, M.; Sambandan, D.; Bangura, F.; Xue, P.; Pi, J.; Kleeberger, S.R.; Bell, D.A. Identification of novel NRF2-regulated genes by ChIP-Seq: Influence on retinoid X receptor alpha. Nucleic Acids Res. 2012, 40, 7416-7429. [CrossRef]

20. Kobayashi, E.H.; Suzuki, T.; Funayama, R.; Nagashima, T.; Hayashi, M.; Sekine, H.; Tanaka, N.; Moriguchi, T.; Motohashi, H.; Nakayama, K.; et al. Nrf2 suppresses macrophage inflammatory response by blocking proinflammatory cytokine transcription. Nat. Commun. 2016, 7, 11624. [CrossRef]

21. Mitsuishi, Y.; Taguchi, K.; Kawatani, Y.; Shibata, T.; Nukiwa, T.; Aburatani, H.; Yamamoto, M.; Motohashi, H. Nrf2 redirects glucose and glutamine into anabolic pathways in metabolic reprogramming. Cancer Cell 2012, 22, 66-79. [CrossRef] [PubMed]

22. Baird, L.; Yamamoto, M. The Molecular Mechanisms Regulating the KEAP1-NRF2 Pathway. Mol. Cell. Biol. 2020, 40, e00099-20. [CrossRef] [PubMed]

23. Huang, H.C.; Nguyen, T.; Pickett, C.B. Phosphorylation of Nrf2 at Ser-40 by protein kinase C regulates antioxidant response element-mediated transcription. J. Biol. Chem. 2002, 277, 42769-42774. [CrossRef] [PubMed]

24. Apopa, P.L.; He, X.; Ma, Q. Phosphorylation of Nrf2 in the transcription activation domain by casein kinase 2 (CK2) is critical for the nuclear translocation and transcription activation function of Nrf2 in IMR-32 neuroblastoma cells. J. Biochem. Mol. Toxicol. 2008, 22, 63-76. [CrossRef]

25. Sun, Z.; Huang, Z.; Zhang, D.D. Phosphorylation of Nrf2 at multiple sites by MAP kinases has a limited contribution in modulating the Nrf2-dependent antioxidant response. PLoS ONE 2009, 4, e6588. [CrossRef] [PubMed]

26. Cullinan, S.B.; Zhang, D.; Hannink, M.; Arvisais, E.; Kaufman, R.J.; Diehl, J.A. Nrf2 is a direct PERK substrate and effector of PERK-dependent cell survival. Mol. Cell. Biol. 2003, 23, 7198-7209. [CrossRef] [PubMed] 
27. Bloom, D.A.; Jaiswal, A.K. Phosphorylation of Nrf2 at Ser40 by protein kinase C in response to antioxidants leads to the release of Nrf2 from INrf2, but is not required for Nrf2 stabilization/accumulation in the nucleus and transcriptional activation of antioxidant response element-mediated NAD $(\mathrm{P}) \mathrm{H}$ :quinone oxidoreductase-1 gene expression. J. Biol. Chem. 2003, 278, 44675-44682. [CrossRef]

28. Yuan, X.; Xu, C.; Pan, Z.; Keum, Y.S.; Kim, J.H.; Shen, G.; Yu, S.; Oo, K.T.; Ma, J.; Kong, A.N. Butylated hydroxyanisole regulates ARE-mediated gene expression via Nrf2 coupled with ERK and JNK signaling pathway in HepG2 cells. Mol. Carcinog. 2006, 45, 841-850. [CrossRef]

29. Zhu, H.; Itoh, K.; Yamamoto, M.; Zweier, J.L.; Li, Y. Role of Nrf2 signaling in regulation of antioxidants and phase 2 enzymes in cardiac fibroblasts: Protection against reactive oxygen and nitrogen species-induced cell injury. FEBS Lett. 2005, 579, 3029-3036. [CrossRef]

30. Agyeman, A.S.; Chaerkady, R.; Shaw, P.G.; Davidson, N.E.; Visvanathan, K.; Pandey, A.; Kensler, T.W. Transcriptomic and proteomic profiling of KEAP1 disrupted and sulforaphane-treated human breast epithelial cells reveals common expression profiles. Breast Cancer Res. Treat. 2012, 132, 175-187. [CrossRef]

31. Malhotra, D.; Portales-Casamar, E.; Singh, A.; Srivastava, S.; Arenillas, D.; Happel, C.; Shyr, C.; Wakabayashi, N.; Kensler, T.W.; Wasserman, W.W.; et al. Global mapping of binding sites for Nrf2 identifies novel targets in cell survival response through ChIP-Seq profiling and network analysis. Nucleic Acids Res. 2010, 38, 5718-5734. [CrossRef] [PubMed]

32. Shih, A.Y.; Johnson, D.A.; Wong, G.; Kraft, A.D.; Jiang, L.; Erb, H.; Johnson, J.A.; Murphy, T.H. Coordinate regulation of glutathione biosynthesis and release by Nrf2-expressing glia potently protects neurons from oxidative stress. J. Neurosci. 2003, 23, 3394-3406. [CrossRef] [PubMed]

33. Ross, D.; Siegel, D. Functions of NQO1 in Cellular Protection and CoQ10 Metabolism and its Potential Role as a Redox Sensitive Molecular Switch. Front. Physiol. 2017, 8, 595. [CrossRef] [PubMed]

34. Araujo, J.; Zhang, M.; Yin, F. Heme Oxygenase-1, Oxidation, Inflammation, and Atherosclerosis. Front. Pharmacol. 2012 , 3, 119. [CrossRef]

35. Hirotsu, Y.; Katsuoka, F.; Funayama, R.; Nagashima, T.; Nishida, Y.; Nakayama, K.; Engel, J.D.; Yamamoto, M. Nrf2-MafG heterodimers contribute globally to antioxidant and metabolic networks. Nucleic Acids Res. 2012, 40, 10228-10239. [CrossRef]

36. Ryter, S.W.; Choi, A.M. Targeting heme oxygenase-1 and carbon monoxide for therapeutic modulation of inflammation. Transl. Res. 2016, 167, 7-34. [CrossRef]

37. Wu, K.C.; Cui, J.Y.; Klaassen, C.D. Beneficial role of Nrf2 in regulating NADPH generation and consumption. Toxicol. Sci. 2011, 123, 590-600. [CrossRef]

38. Chanas, S.A.; Jiang, Q.; McMahon, M.; McWalter, G.K.; McLellan, L.I.; Elcombe, C.R.; Henderson, C.J.; Wolf, C.R.; Moffat, G.J.; Itoh, K.; et al. Loss of the Nrf2 transcription factor causes a marked reduction in constitutive and inducible expression of the glutathione S-transferase Gsta1, Gsta2, Gstm1, Gstm2, Gstm3 and Gstm4 genes in the livers of male and female mice. Biochem. J. 2002, 365, 405-416. [CrossRef]

39. Thimmulappa, R.K.; Scollick, C.; Traore, K.; Yates, M.; Trush, M.A.; Liby, K.T.; Sporn, M.B.; Yamamoto, M.; Kensler, T.W.; Biswal, S. Nrf2-dependent protection from LPS induced inflammatory response and mortality by CDDO-Imidazolide. Biochem. Biophys. Res. Commun. 2006, 351, 883-889. [CrossRef]

40. Banning, A.; Brigelius-Flohe, R. NF-kappaB, Nrf2, and HO-1 interplay in redox-regulated VCAM-1 expression. Antioxid. Redox Signal. 2005, 7, 889-899. [CrossRef]

41. Kim, J.E.; You, D.J.; Lee, C.; Ahn, C.; Seong, J.Y.; Hwang, J.I. Suppression of NF-kappaB signaling by KEAP1 regulation of IKKbeta activity through autophagic degradation and inhibition of phosphorylation. Cell. Signal. 2010, 22, 1645-1654. [CrossRef] [PubMed]

42. Hwang, Y.J.; Lee, E.W.; Song, J.; Kim, H.R.; Jun, Y.C.; Hwang, K.A. MafK positively regulates NF-kappaB activity by enhancing CBP-mediated p65 acetylation. Sci. Rep. 2013, 3, 3242. [CrossRef] [PubMed]

43. Liu, G.H.; Qu, J.; Shen, X. NF-kappaB/p65 antagonizes Nrf2-ARE pathway by depriving CBP from Nrf2 and facilitating recruitment of HDAC3 to MafK. Biochim. et Biophys. Acta 2008, 1783, 713-727. [CrossRef] [PubMed]

44. Kim, W.; Lee, H.N.; Jang, J.H.; Kim, S.H.; Lee, Y.H.; Hahn, Y.I.; Ngo, H.K.; Choi, Y.; Joe, Y.; Chung, H.T.; et al. 15-DeoxyDelta(12,14)-Prostaglandin J2 Exerts Proresolving Effects Through Nuclear Factor E2-Related Factor 2-Induced Expression of CD36 and Heme Oxygenase-1. Antioxid. Redox Signal. 2017, 27, 1412-1431. [CrossRef] [PubMed]

45. Rockwell, C.E.; Zhang, M.; Fields, P.E.; Klaassen, C.D. Th2 skewing by activation of Nrf2 in CD4(+) T cells. J. Immunol. 2012, 188, 1630-1637. [CrossRef]

46. Ma, Q.; Battelli, L.; Hubbs, A.F. Multiorgan autoimmune inflammation, enhanced lymphoproliferation, and impaired homeostasis of reactive oxygen species in mice lacking the antioxidant-activated transcription factor Nrf2. Am. J. Pathol. 2006, 168, 1960-1974. [CrossRef]

47. Izui, S.; Kelley, V.E.; Masuda, K.; Yoshida, H.; Roths, J.B.; Murphy, E.D. Induction of various autoantibodies by mutant gene lpr in several strains of mice. J. Immunol. 1984, 133, 227-233.

48. Han, S.; Zhuang, H.; Lee, P.Y.; Li, M.; Yang, L.; Nigrovic, P.A.; Reeves, W.H. NF-E2-Related Factor 2 Regulates Interferon Receptor Expression and Alters Macrophage Polarization in Lupus. Arthritis Rheumatol. 2020, 72, 1707-1720. [CrossRef] 
49. Klemm, P.; Rajendiran, A.; Fragoulis, A.; Wruck, C.; Schippers, A.; Wagner, N.; Bopp, T.; Tenbrock, K.; Ohl, K. Nrf2 expression driven by Foxp3 specific deletion of Keap1 results in loss of immune tolerance in mice. Eur. J. Immunol. 2020, 50, 515-524. [CrossRef]

50. Morzadec, C.; Macoch, M.; Sparfel, L.; Kerdine-Romer, S.; Fardel, O.; Vernhet, L. Nrf2 expression and activity in human T lymphocytes: Stimulation by $\mathrm{T}$ cell receptor activation and priming by inorganic arsenic and tert-butylhydroquinone. Free Radic. Biol. Med. 2014, 71, 133-145. [CrossRef]

51. Tsai, J.J.; Velardi, E.; Shono, Y.; Argyropoulos, K.V.; Holland, A.M.; Smith, O.M.; Yim, N.L.; Rao, U.K.; Kreines, F.M.; Lieberman, S.R.; et al. Nrf2 regulates CD4(+) T cell-induced acute graft-versus-host disease in mice. Blood 2018, 132, $2763-2774$. [CrossRef] [PubMed]

52. Noel, S.; Martina, M.N.; Bandapalle, S.; Racusen, L.C.; Potteti, H.R.; Hamad, A.R.; Reddy, S.P.; Rabb, H. T Lymphocyte-Specific Activation of Nrf2 Protects from AKI. J. Am. Soc. Nephrol. 2015, 26, 2989-3000. [CrossRef] [PubMed]

53. Suzuki, T.; Murakami, S.; Biswal, S.S.; Sakaguchi, S.; Harigae, H.; Yamamoto, M.; Motohashi, H. Systemic Activation of NRF2 Alleviates Lethal Autoimmune Inflammation in Scurfy Mice. Mol. Cell. Biol. 2017, 37, e00063-17. [CrossRef]

54. Ohl, K.; Fragoulis, A.; Klemm, P.; Baumeister, J.; Klock, W.; Verjans, E.; Boll, S.; Mollmann, J.; Lehrke, M.; Costa, I.; et al. Nrf2 Is a Central Regulator of Metabolic Reprogramming of Myeloid-Derived Suppressor Cells in Steady State and Sepsis. Front. Immunol. 2018, 9, 1552. [CrossRef]

55. Li, J.; Stein, T.D.; Johnson, J.A. Genetic dissection of systemic autoimmune disease in Nrf2-deficient mice. Physiol. Genom. 2004, 18, 261-272. [CrossRef] [PubMed]

56. Flemming, A.; Brummer, T.; Reth, M.; Jumaa, H. The adaptor protein SLP-65 acts as a tumor suppressor that limits pre-B cell expansion. Nat. Immunol. 2003, 4, 38-43. [CrossRef] [PubMed]

57. Fraser, P.A.; Ding, W.Z.; Mohseni, M.; Treadwell, E.L.; Dooley, M.A.; St Clair, E.W.; Gilkeson, G.S.; Cooper, G.S. Glutathione S-transferase M null homozygosity and risk of systemic lupus erythematosus associated with sun exposure: A possible geneenvironment interaction for autoimmunity. J. Rheumatol. 2003, 30, 276-282.

58. Watanabe-Fukunaga, R.; Brannan, C.I.; Copeland, N.G.; Jenkins, N.A.; Nagata, S. Lymphoproliferation disorder in mice explained by defects in Fas antigen that mediates apoptosis. Nature 1992, 356, 314-317. [CrossRef]

59. Morito, N.; Yoh, K.; Hirayama, A.; Itoh, K.; Nose, M.; Koyama, A.; Yamamoto, M.; Takahashi, S. Nrf2 deficiency improves autoimmune nephritis caused by the fas mutation lpr. Kidney Int. 2004, 65, 1703-1713. [CrossRef]

60. Zhao, M.; Chen, H.; Ding, Q.; Xu, X.; Yu, B.; Huang, Z. Nuclear Factor Erythroid 2-related Factor 2 Deficiency Exacerbates Lupus Nephritis in B6/lpr mice by Regulating Th17 Cell Function. Sci. Rep. 2016, 6, 38619. [CrossRef]

61. Kelley, V.E.; Roths, J.B. Interaction of mutant lpr gene with background strain influences renal disease. Clin. Immunol. Immunopathol. 1985, 37, 220-229. [CrossRef]

62. Satoh, M.; Kumar, A.; Kanwar, Y.S.; Reeves, W.H. Anti-nuclear antibody production and immune-complex glomerulonephritis in BALB/c mice treated with pristane. Proc. Natl. Acad. Sci. USA 1995, 92, 10934-10938. [CrossRef] [PubMed]

63. Castejon, M.L.; Sánchez-Hidalgo, M.; Aparicio-Soto, M.; Montoya, T.; Martín-LaCave, I.; Fernández-Bolaños, J.G.; Alarcón-dela-Lastra, C. Dietary oleuropein and its new acyl-derivate attenuate murine lupus nephritis through HO-1/Nrf2 activation and suppressing JAK/STAT, NF-кB, MAPK and NLRP3 inflammasome signaling pathways. J. Nutr. Biochem. 2019, 74, 108229. [CrossRef] [PubMed]

64. Li, D.; Shi, G.; Wang, J.; Zhang, D.; Pan, Y.; Dou, H.; Hou, Y. Baicalein ameliorates pristane-induced lupus nephritis via activating Nrf2/HO-1 in myeloid-derived suppressor cells. Arthritis Res. Ther. 2019, 21, 105. [CrossRef]

65. Aparicio-Soto, M.; Sanchez-Hidalgo, M.; Cardeno, A.; Rosillo, M.A.; Sanchez-Fidalgo, S.; Utrilla, J.; Martin-Lacave, I.; Alarcon-dela-Lastra, C. Dietary extra virgin olive oil attenuates kidney injury in pristane-induced SLE model via activation of HO-1/Nrf-2 antioxidant pathway and suppression of JAK/STAT, NF-kappaB and MAPK activation. J. Nutr. Biochem. 2016, 27, 278-288. [CrossRef]

66. Ebihara, S.; Tajima, H.; Ono, M. Nuclear factor erythroid 2-related factor 2 is a critical target for the treatment of glucocorticoidresistant lupus nephritis. Arthritis Res. Ther. 2016, 18, 139. [CrossRef]

67. Li, D.; Qi, J.; Wang, J.; Pan, Y.; Li, J.; Xia, X.; Dou, H.; Hou, Y. Protective effect of dihydroartemisinin in inhibiting senescence of myeloid-derived suppressor cells from lupus mice via Nrf2/HO-1 pathway. Free Radic. Biol. Med. 2019, 143, 260-274. [CrossRef]

68. Tsai, P.Y.; Ka, S.M.; Chang, J.M.; Lai, J.H.; Dai, M.S.; Jheng, H.L.; Kuo, M.T.; Chen, P.; Chen, A. Antroquinonol differentially modulates $\mathrm{T}$ cell activity and reduces interleukin-18 production, but enhances Nrf2 activation, in murine accelerated severe lupus nephritis. Arthritis Rheum. 2012, 64, 232-242. [CrossRef]

69. Ka, S.M.; Lin, J.C.; Lin, T.J.; Liu, F.C.; Chao, L.K.; Ho, C.L.; Yeh, L.T.; Sytwu, H.K.; Hua, K.F.; Chen, A. Citral alleviates an accelerated and severe lupus nephritis model by inhibiting the activation signal of NLRP3 inflammasome and enhancing Nrf2 activation. Arthritis Res. Ther. 2015, 17, 331. [CrossRef]

70. Tsai, P.Y.; Ka, S.M.; Chang, J.M.; Chen, H.C.; Shui, H.A.; Li, C.Y.; Hua, K.F.; Chang, W.L.; Huang, J.J.; Yang, S.S.; et al Epigallocatechin-3-gallate prevents lupus nephritis development in mice via enhancing the Nrf2 antioxidant pathway and inhibiting NLRP3 inflammasome activation. Free Radic. Biol. Med. 2011, 51, 744-754. [CrossRef]

71. Dong, Y.; Zhang, Z.; Liu, H.; Jia, L.; Qin, M.; Wang, X. Exacerbating lupus nephritis following BPA exposure is associated with abnormal autophagy in MRL/lpr mice. Am. J. Transl. Res. 2020, 12, 649-659. [PubMed] 
72. Banerjee, N.; Wang, H.; Wang, G.; Boor, P.J.; Khan, M.F. Redox-sensitive Nrf2 and MAPK signaling pathways contribute to trichloroethene-mediated autoimmune disease progression. Toxicology 2021, 457, 152804. [CrossRef] [PubMed]

73. Ene, C.D.; Georgescu, S.R.; Tampa, M.; Matei, C.; Mitran, C.I.; Mitran, M.I.; Penescu, M.N.; Nicolae, I. Cellular Response against Oxidative Stress, a Novel Insight into Lupus Nephritis Pathogenesis. J. Pers. Med. 2021, 11, 693. [CrossRef]

74. Gautam, P.; Kaur, G.; Tandon, A.; Sharma, A.; Bhatnagar, A. Altered redox regulation by Nrf2-Keap1 system in dendritic cells of systemic lupus erythematosus patients. Lupus 2020, 29, 1544-1555. [CrossRef] [PubMed]

75. Tandon, A.; Anupam, K.; Kaushal, J.; Gautam, P.; Sharma, A.; Bhatnagar, A. Altered oxidative stress markers in relation to T cells, NK cells \& killer immunoglobulin receptors that are associated with disease activity in SLE patients. Lupus 2020, 29, 1831-1844. [CrossRef] [PubMed]

76. De Oliveira, M.A.A.; Mallmann, N.H.; de Souza, G.; de Jesus Bacha, T.; Lima, E.S.; de Lima, D.S.N.; de Souza Passos, L.F.; de Souza Gonçalves, M.; de Moura Neto, J.P. Glutathione S-transferase, catalase, and mitochondrial superoxide dismutase gene polymorphisms modulate redox potential in systemic lupus erythematosus patients from Manaus, Amazonas, Brazil. Clin. Rheumatol. 2021, 40, 3639-3649. [CrossRef] [PubMed]

77. Warchoł, T.; Lianeri, M.; Wudarski, M.; Lacki, J.K.; Jagodziński, P.P. Catalase -262C >T polymorphism in systemic lupus erythematosus in Poland. Rheumatol. Int. 2008, 28, 1035-1039. [CrossRef] [PubMed]

78. Kim-Howard, X.; Sun, C.; Molineros, J.E.; Maiti, A.K.; Chandru, H.; Adler, A.; Wiley, G.B.; Kaufman, K.M.; Kottyan, L.; Guthridge, J.M.; et al. Allelic heterogeneity in NCF2 associated with systemic lupus erythematosus (SLE) susceptibility across four ethnic populations. Hum. Mol. Genet. 2014, 23, 1656-1668. [CrossRef]

79. Córdova, E.J.; Velázquez-Cruz, R.; Centeno, F.; Baca, V.; Orozco, L. The NRF2 gene variant, -653G/A, is associated with nephritis in childhood-onset systemic lupus erythematosus. Lupus 2010, 19, 1237-1242. [CrossRef]

80. Yamamoto, T.; Yoh, K.; Kobayashi, A.; Ishii, Y.; Kure, S.; Koyama, A.; Sakamoto, T.; Sekizawa, K.; Motohashi, H.; Yamamoto, M. Identification of polymorphisms in the promoter region of the human NRF2 gene. Biochem. Biophys. Res. Commun. 2004, 321, 72-79. [CrossRef]

81. Martini, S.; Nair, V.; Keller, B.J.; Eichinger, F.; Hawkins, J.J.; Randolph, A.; Böger, C.A.; Gadegbeku, C.A.; Fox, C.S.; Cohen, C.D.; et al. Integrative biology identifies shared transcriptional networks in CKD. J. Am. Soc. Nephrol. 2014, 25, $2559-2572$. [CrossRef] [PubMed]

82. Zhang, D.D.; Hannink, M. Distinct cysteine residues in Keap1 are required for Keap1-dependent ubiquitination of Nrf2 and for stabilization of Nrf2 by chemopreventive agents and oxidative stress. Mol. Cell. Biol. 2003, 23, 8137-8151. [CrossRef] [PubMed]

83. Eggler, A.L.; Liu, G.; Pezzuto, J.M.; van Breemen, R.B.; Mesecar, A.D. Modifying specific cysteines of the electrophile-sensing human Keap1 protein is insufficient to disrupt binding to the Nrf2 domain Neh2. Proc. Natl. Acad. Sci. USA 2005, 102, 10070-10075. [CrossRef] [PubMed]

84. Saito, R.; Suzuki, T.; Hiramoto, K.; Asami, S.; Naganuma, E.; Suda, H.; Iso, T.; Yamamoto, H.; Morita, M.; Baird, L.; et al Characterizations of Three Major Cysteine Sensors of Keap1 in Stress Response. Mol. Cell. Biol. 2016, 36, 271-284. [CrossRef]

85. Suzuki, T.; Yamamoto, M. Stress-sensing mechanisms and the physiological roles of the Keap1-Nrf2 system during cellular stress. J. Biol. Chem. 2017, 292, 16817-16824. [CrossRef]

86. Hourihan, J.M.; Kenna, J.G.; Hayes, J.D. The gasotransmitter hydrogen sulfide induces nrf2-target genes by inactivating the keap1 ubiquitin ligase substrate adaptor through formation of a disulfide bond between cys-226 and cys-613. Antioxid. Redox Signal. 2013, 19, 465-481. [CrossRef]

87. Hu, L.; Magesh, S.; Chen, L.; Wang, L.; Lewis, T.A.; Chen, Y.; Khodier, C.; Inoyama, D.; Beamer, L.J.; Emge, T.J.; et al. Discovery of a small-molecule inhibitor and cellular probe of Keap1-Nrf2 protein-protein interaction. Bioorg. Med. Chem. Lett. 2013, 23, 3039-3043. [CrossRef]

88. Inoyama, D.; Chen, Y.; Huang, X.; Beamer, L.J.; Kong, A.N.; Hu, L. Optimization of fluorescently labeled Nrf2 peptide probes and the development of a fluorescence polarization assay for the discovery of inhibitors of Keap1-Nrf2 interaction. J. Biomol. Screen 2012, 17, 435-447. [CrossRef]

89. Jiang, Z.Y.; Lu, M.C.; Xu, L.L.; Yang, T.T.; Xi, M.Y.; Xu, X.L.; Guo, X.K.; Zhang, X.J.; You, Q.D.; Sun, H.P. Discovery of potent Keap1-Nrf2 protein-protein interaction inhibitor based on molecular binding determinants analysis. J. Med. Chem. 2014, 57, 2736-2745. [CrossRef]

90. Chen, W.; Sun, Z.; Wang, X.J.; Jiang, T.; Huang, Z.; Fang, D.; Zhang, D.D. Direct interaction between Nrf2 and p21(Cip1/WAF1) upregulates the Nrf2-mediated antioxidant response. Mol. Cell 2009, 34, 663-673. [CrossRef]

91. Bader, S.; Wilmers, J.; Pelzer, M.; Jendrossek, V.; Rudner, J. Activation of anti-oxidant Keap1/Nrf2 pathway modulates efficacy of dihydroartemisinin-based monotherapy and combinatory therapy with ionizing radiation. Free Radic. Biol. Med. 2021, 168, 44-54. [CrossRef] [PubMed]

92. Bruijn, J.A.; van Elven, E.H.; Hogendoorn, P.C.; Corver, W.E.; Hoedemaeker, P.J.; Fleuren, G.J. Murine chronic graft-versus-host disease as a model for lupus nephritis. Am. J. Pathol. 1988, 130, 639-641. [PubMed]

93. Wu, X.; Zhang, W.; Shi, X.; An, P.; Sun, W.; Wang, Z. Therapeutic effect of artemisinin on lupus nephritis mice and its mechanisms. Acta Biochim. Biophys. Sin. 2010, 42, 916-923. [CrossRef] [PubMed]

94. Jin, O.; Zhang, H.; Gu, Z.; Zhao, S.; Xu, T.; Zhou, K.; Jiang, B.; Wang, J.; Zeng, X.; Sun, L. A pilot study of the therapeutic efficacy and mechanism of artesunate in the MRL/lpr murine model of systemic lupus erythematosus. Cell Mol. Immunol. 2009, 6, 461-467. [CrossRef] [PubMed] 
95. Wu, Y.; He, S.; Bai, B.; Zhang, L.; Xue, L.; Lin, Z.; Yang, X.; Zhu, F.; He, P.; Tang, W.; et al. Therapeutic effects of the artemisinin analog SM934 on lupus-prone MRL/lpr mice via inhibition of TLR-triggered B-cell activation and plasma cell formation. Cell. Mol. Immunol. 2016, 13, 379-390. [CrossRef] [PubMed]

96. Dang, W.Z.; Li, H.; Jiang, B.; Nandakumar, K.S.; Liu, K.F.; Liu, L.X.; Yu, X.C.; Tan, H.J.; Zhou, C. Therapeutic effects of artesunate on lupus-prone MRL/lpr mice are dependent on T follicular helper cell differentiation and activation of JAK2-STAT3 signaling pathway. Phytomedicine 2019, 62, 152965. [CrossRef]

97. Ichimura, Y.; Waguri, S.; Sou, Y.S.; Kageyama, S.; Hasegawa, J.; Ishimura, R.; Saito, T.; Yang, Y.; Kouno, T.; Fukutomi, T.; et al Phosphorylation of p62 activates the Keap1-Nrf2 pathway during selective autophagy. Mol. Cell 2013, 51, 618-631. [CrossRef]

98. Houghton, C.A.; Fassett, R.G.; Coombes, J.S. Sulforaphane: Translational research from laboratory bench to clinic. Nutr. Rev. 2013, 71, 709-726. [CrossRef]

99. Bomprezzi, R. Dimethyl fumarate in the treatment of relapsing-remitting multiple sclerosis: An overview. Adv. Neurol. Disord. 2015, 8, 20-30. [CrossRef]

100. Hong, D.S.; Kurzrock, R.; Supko, J.G.; He, X.; Naing, A.; Wheler, J.; Lawrence, D.; Eder, J.P.; Meyer, C.J.; Ferguson, D.A.; et al. A phase I first-in-human trial of bardoxolone methyl in patients with advanced solid tumors and lymphomas. Clin. Cancer Res. 2012, 18, 3396-3406. [CrossRef]

101. Liby, K.T.; Sporn, M.B. Synthetic oleanane triterpenoids: Multifunctional drugs with a broad range of applications for prevention and treatment of chronic disease. Pharm. Rev. 2012, 64, 972-1003. [CrossRef]

102. Nangaku, M.; Kanda, H.; Takama, H.; Ichikawa, T.; Hase, H.; Akizawa, T. Randomized Clinical Trial on the Effect of Bardoxolone Methyl on GFR in Diabetic Kidney Disease Patients (TSUBAKI Study). Kidney Int. Rep. 2020, 5, 879-890. [CrossRef] [PubMed]

103. Kanlaya, R.; Khamchun, S.; Kapincharanon, C.; Thongboonkerd, V. Protective effect of epigallocatechin-3-gallate (EGCG) via Nrf2 pathway against oxalate-induced epithelial mesenchymal transition (EMT) of renal tubular cells. Sci. Rep. 2016, 6, 30233. [CrossRef] [PubMed]

104. Efferth, T.; Oesch, F. The immunosuppressive activity of artemisinin-type drugs towards inflammatory and autoimmune diseases. Med. Res. Rev. 2021, 41, 3023-3061. [CrossRef] [PubMed]

105. Lin, Z.; Liu, Y.; Chen, L.; Cao, S.; Huang, Y.; Yang, X.; Zhu, F.; Tang, W.; He, S.; Zuo, J. Artemisinin analogue SM934 protects against lupus-associated antiphospholipid syndrome via activation of Nrf2 and its targets. Sci. China Life Sci. 2021, 64, 1702-1719. [CrossRef] [PubMed]

106. Zhang, H.; Qi, S.; Song, Y.; Ling, C. Artemisinin attenuates early renal damage on diabetic nephropathy rats through suppressing TGF-beta1 regulator and activating the Nrf2 signaling pathway. Life Sci. 2020, 256, 117966. [CrossRef]

107. Su, X.; Guo, W.; Yuan, B.; Wang, D.; Liu, L.; Wu, X.; Zhang, Y.; Kong, X.; Lin, N. Artesunate attenuates bone erosion in rheumatoid arthritis by suppressing reactive oxygen species via activating p62/Nrf2 signaling. Biomed. Pharm. 2021, 137, 111382. [CrossRef]

108. Li, W.D.; Dong, Y.J.; Tu, Y.Y.; Lin, Z.B. Dihydroarteannuin ameliorates lupus symptom of BXSB mice by inhibiting production of TNF-alpha and blocking the signaling pathway NF-kappa B translocation. Int. Immunopharmacol. 2006, 6, 1243-1250. [CrossRef]

109. Hou, L.F.; He, S.J.; Li, X.; Yang, Y.; He, P.L.; Zhou, Y.; Zhu, F.H.; Yang, Y.F.; Li, Y.; Tang, W.; et al. Oral administration of artemisinin analog SM934 ameliorates lupus syndromes in MRL/lpr mice by inhibiting Th1 and Th17 cell responses. Arthritis Rheum. 2011, 63, 2445-2455. [CrossRef]

110. Feng, X.; Chen, W.; Xiao, L.; Gu, F.; Huang, J.; Tsao, B.P.; Sun, L. Artesunate inhibits type I interferon-induced production of macrophage migration inhibitory factor in patients with systemic lupus erythematosus. Lupus 2017, 26, 62-72. [CrossRef]

111. Tang, C.; Wang, X.; Xie, Y.; Cai, X.; Yu, N.; Hu, Y.; Zheng, Z. 4-Octyl Itaconate Activates Nrf2 Signaling to Inhibit Pro-Inflammatory Cytokine Production in Peripheral Blood Mononuclear Cells of Systemic Lupus Erythematosus Patients. Cell. Physiol. Biochem. 2018, 51, 979-990. [CrossRef] [PubMed]

112. Walker, F.; Adamczyk, A.; Kellerer, C.; Belge, K.; Bruck, J.; Berner, T.; Merten, K.; Nunez Gomez, N.; Neureither, M.; Rocken, M.; et al. Fumaderm(R) in daily practice for psoriasis: Dosing, efficacy and quality of life. Br. J. Derm. 2014, 171, 1197-1205. [CrossRef]

113. Tsianakas, A.; Herzog, S.; Landmann, A.; Patsinakidis, N.; Perusquia Ortiz, A.M.; Bonsmann, G.; Luger, T.A.; Kuhn, A. Successful treatment of discoid lupus erythematosus with fumaric acid esters. J. Am. Acad. Derm. 2014, 71, e15-e17. [CrossRef]

114. Saracino, A.M.; Orteu, C.H. Severe recalcitrant cutaneous manifestations in systemic lupus erythematosus successfully treated with fumaric acid esters. Br. J. Derm. 2017, 176, 472-480. [CrossRef]

115. Pergola, P.E.; Krauth, M.; Huff, J.W.; Ferguson, D.A.; Ruiz, S.; Meyer, C.J.; Warnock, D.G. Effect of bardoxolone methyl on kidney function in patients with T2D and Stage 3b-4 CKD. Am. J. Nephrol. 2011, 33, 469-476. [CrossRef] [PubMed]

116. Pergola, P.E.; Raskin, P.; Toto, R.D.; Meyer, C.J.; Huff, J.W.; Grossman, E.B.; Krauth, M.; Ruiz, S.; Audhya, P.; Christ-Schmidt, H.; et al. Bardoxolone methyl and kidney function in CKD with type 2 diabetes. N. Engl. J. Med. 2011, 365, 327-336. [CrossRef] [PubMed]

117. Chin, M.P.; Reisman, S.A.; Bakris, G.L.; O'Grady, M.; Linde, P.G.; McCullough, P.A.; Packham, D.; Vaziri, N.D.; Ward, K.W.; Warnock, D.G.; et al. Mechanisms contributing to adverse cardiovascular events in patients with type 2 diabetes mellitus and stage 4 chronic kidney disease treated with bardoxolone methyl. Am. J. Nephrol. 2014, 39, 499-508. [CrossRef]

118. De Zeeuw, D.; Akizawa, T.; Audhya, P.; Bakris, G.L.; Chin, M.; Christ-Schmidt, H.; Goldsberry, A.; Houser, M.; Krauth, M.; Lambers Heerspink, H.J.; et al. Bardoxolone methyl in type 2 diabetes and stage 4 chronic kidney disease. N. Engl. J. Med. 2013, 369, 2492-2503. [CrossRef] 
119. Yagishita, Y.; Gatbonton-Schwager, T.N.; McCallum, M.L.; Kensler, T.W. Current Landscape of NRF2 Biomarkers in Clinical Trials. Antioxidants 2020, 9, 716. [CrossRef]

120. To, C.; Ringelberg, C.S.; Royce, D.B.; Williams, C.R.; Risingsong, R.; Sporn, M.B.; Liby, K.T. Dimethyl fumarate and the oleanane triterpenoids, CDDO-imidazolide and CDDO-methyl ester, both activate the Nrf2 pathway but have opposite effects in the A/J model of lung carcinogenesis. Carcinogenesis 2015, 36, 769-781. [CrossRef] 